\title{
Angularly-Resolved E $\times$ B Probe Spectra in the Plume of a 6-kW Hall Thruster
}

\author{
Bryan M. Reid, ${ }^{1}$ Rohit Shastry, ${ }^{2}$ Alec D. Gallimore ${ }^{3}$ \\ University of Michigan, Ann Arbor, MI 48109 \\ and \\ Richard R. Hofer ${ }^{4}$ \\ Jet Propulsion Laboratory, California Institute of Technology, Pasadena, CA 91109
}

\begin{abstract}
An $\mathbf{E} \times \mathbf{B}$ probe was used to characterize the angular distribution of multiply-charged ions in the plume of a 6-kW Hall thruster operating at discharge voltages of 150-600 V, and anode mass flow rates of $10-30 \mathrm{mg} / \mathrm{s}$. The local ion current fractions were measured in conjunction with ion current density at several locations from $0-30^{\circ}$ from thruster centerline, and axial locations of 8,10 , and 12 thruster diameters. Typically the fraction of $\mathrm{Xe}^{2+}$ increased by the drop in $\mathrm{Xe}^{1+}$, while $\mathrm{Xe}^{3+}$ remained approximately constant at all angles. The current fraction of $\mathrm{Xe}^{1+}$ decreased with increased discharge voltage, having values of 0.92 , 0.87 , and 0.70 at 150,300 , and $600 \mathrm{~V}$, respectively. The plume-averaged $\mathrm{Xe}^{1+}$ current fraction also decreased with increased flow rate, having fractions of $0.87,0.75$, and 0.60 at 10,20 , and $30 \mathrm{mg} / \mathrm{s}$, respectively. The increasing fraction of multiply-charged ions with discharge voltage was attributed to the increase in electron temperature. The increasing fraction of multiply-charged ions with anode flow rate was explained by the increasing ratio of $\mathrm{Xe}^{1+}$ to neutral Xe found by plasma simulations in HPHall. The results were corrected for the loss of main beam ions due to charge-exchange collisions between the thruster exit and probe location. The correction method performed well, producing plume-averaged correction factors that were within $0.5 \%$ of each other with the probe positioned at 8,10 , and 12 thruster diameters downstream. The correction due to charge-exchange collisions was on the order of $1-5 \%$, depending on operating condition, exceeding the errors introduced by other parameters used in performance models. The plume-averaged correction for multiply-charged ions deviated from the discharge channel centerline value by approximately $1.5 \%$ over a range of discharge powers from 1 to $10 \mathrm{~kW}$, with the maximum deviation of $5 \%$ occurring at the $600 \mathrm{~V}, 10 \mathrm{mg} / \mathrm{s}$ condition. The results indicate that a single measurement of the local ion current fractions near discharge channel centerline is sufficient to accurately gauge the overall correction for multiply-charged ion species. While this is true for studies that are concerned with the behavior of the thruster over large throttling ranges, plume-averaged quantities are likely to be a necessity for studies focused on fine changes in thruster performance.
\end{abstract}

\footnotetext{
${ }^{1}$ Ph. D. Candidate, Plasmadynamics and Electric Propulsion Laboratory, reidb@umich.edu, and AIAA student member.

${ }^{2}$ Ph. D. Candidate, Plasmadynamics and Electric Propulsion Laboratory, rshastry@umich.edu, and AIAA student member.

3 Arthur F. Thurnau Professor of Aerospace Engineering and Director of the Plasmadynamics and Electric Propulsion Laboratory, alec.gallimore@umich.edu. AIAA Associate Fellow.

${ }^{4}$ Technical Staff Member, Electric Propulsion Group, 4800 Oak Grove Dr., MS 125-109, Pasadena, CA 91109 , richard.r.hofer@jpl.nasa.gov. AIAA senior member.
} 


\section{Nomenclature}

$\begin{array}{ll}B & =\text { magnetic field } \\ e & =\text { electron charge } \\ E & =\text { electric field } \\ F & =\text { Lorentz force } \\ I_{b} & =\text { ion beam current } \\ I_{d} & =\text { discharge current } \\ j & =\text { ion current density } \\ m_{x e} & =\text { mass of xenon atom } \\ \dot{m}_{a} & =\text { anode mass flow rate } \\ n_{e} & =\text { plasma density } \\ n_{n} & =\text { neutral density } \\ n_{i} & =\text { ion density } \\ \dot{n}_{i} & =\text { ion flow rate density } \\ P & =\text { facility pressure, } 10^{-5} \text { torr } \\ P_{d} & =\text { discharge power } \\ Q & =\text { effective charge state } \\ R & =\text { radial location from thruster centerline }\end{array}$

$\begin{array}{ll}T & =\text { thrust } \\ u & =\text { test particle velocity } \\ V_{l} & =\text { ion loss voltage } \\ V_{d} & =\text { discharge voltage } \\ Z & =\text { axial distance from thruster exit plane } \\ Z_{i} & =\text { charge-state of the } \mathrm{i}^{\text {th }} \text { ion species } \\ \alpha\left(T_{e}\right)= & \text { ionization rate parameter } \\ \alpha_{\mathrm{m}} & =\text { mass utilization correction factor, } \Sigma(\Omega / Z) \\ \eta_{a} & =\text { anode efficiency } \\ \eta_{b} & =\text { beam utilization efficiency } \\ \eta_{m} & =\text { mass utilization efficiency } \\ \eta_{q} & =\text { charge utilization efficiency } \\ \eta_{v} & =\text { voltage utilization efficiency } \\ \zeta_{i} & =\text { species fraction of } \mathrm{i}^{\text {th }} \text { ion species } \\ \Omega_{\mathrm{i}} & =\text { current fraction of } \mathrm{i}^{\text {th }} \text { ion species } \\ \Omega_{i, a v g} & =\text { plume-averaged current fraction } \\ \Omega_{i, l o c} & =\text { local current fraction of } \mathrm{i}^{\text {th }} \text { ion species }\end{array}$

\section{Introduction}

$\mathrm{H}$ ALL thrusters are now being adopted and flown by most major communications satellite manufacturers and were flown on the European Space Agency's technology demonstration mission SMART-1 [1]. As their usage has increased, the need for accurate ground testing and plume characterization of Hall thrusters has become more important. To identify potential plasma-spacecraft interaction issues and more importantly, characterize the properties that contribute to performance models [2-4], angularly-resolved plasma measurements are needed. Of primary interest to these performance models is the angular variation of ion current density, ion energy, and the charge state of the ion species. This study focuses on understanding the angular variation of the ion species as measured by an $\mathrm{E} \times \mathrm{B}$ probe in the plume of a Hall thruster.

The angular variation of the ion species has been previously studied using $\mathrm{E} \times \mathrm{B}$ probes [5, 6], but its influence on integral performance characteristics has not been emphasized. This experiment uses the angular variation of ion species to determine plume-averaged ion current fractions for use in performance analyses. Data were taken over a wide range of anode flow rates $(10-30 \mathrm{mg} / \mathrm{s})$ and at several axial locations $(8,10$, and 12 thruster diameters) to test the influence of facility-induced Charge-Exchange (CEX) collisions with main beam ions. The collection of these data were also meant to confirm the results and recommendations laid out by Shastry et al. [7], with the end-goal of presenting a unified measurement technique and analysis methodology for $\mathrm{E} \times \mathrm{B}$ probe spectra. Another goal of this experiment was to determine the potential error introduced by taking single-point $\mathrm{E} \times \mathrm{B}$ measurements on thruster centerline when compared to taking angularly-resolved measurements.

In the following, a detailed description of the experimental apparatus and probe operation are discussed followed by a presentation of the experimental results and discussion. The results section begins with a brief discussion of the difference between current fractions and species fractions and several important parameters that combine the effect of multiply-charged ions. This is followed by a comparison of $\mathrm{E} \times \mathrm{B}$ probe spectra at various discharge voltages, anode mass flow rates, and angular locations. The ion current fractions are presented for each operating condition. The discussion section focuses on the influence of thruster operating condition on the plume-averaged $\alpha_{\mathrm{m}}$ and a comparison with $\mathrm{E} \times \mathrm{B}$ data from the Jet Propulsion Laboratory (JPL) and plasma simulations from HPHall [3].

\section{Experimental Apparatus}

\section{A. Vacuum Facility}

Experiments were performed in the Large Vacuum Test Facility (LVTF) at the University of Michigan (UM) Plasmadynamics and Electric Propulsion Laboratory (PEPL). The LVTF is a 6-m-diameter, 9-m-long, cylindrical, stainless steel chamber. Pumping is provided by seven single-stage CVI model TM-1200 cryo-pumps and liquid nitrogen shrouds, with a nominal pumping speed of $240,000 \mathrm{l} / \mathrm{s}$ on xenon. The facility base pressure was approximately $2.3 \times 10^{-7}$ torr, as measured by two hot cathode ionization gauges. The first gauge, referred to as the "external' gauge is a Varian model 571 gauge with a HPS 919 hot cathode controller. The second gauge, referred to 
as the "nude" gauge, is a Varian model UHV-24 nude ionization gauge with a Varian UHV senTorr Vacuum gauge controller. More details on the facility and pressure monitoring equipment can be found in Ref. [8].

The facility pressure measured by both gauges is shown in Figure 1 along with the average of the two gauges that is used as the facility pressure in the CEX corrections discussed later. The average pressure from the gauges has historically been used at PEPL [8] since the average yields an effective pumping speed of 220,000 1/s, which is $10 \%$ within the nominal pumping speed of the facility. Over the range of flow rates tested, the facility pressure increased linearly with flow rate. The uncertainty of the pressure measurement is estimated to be $20 \%$.

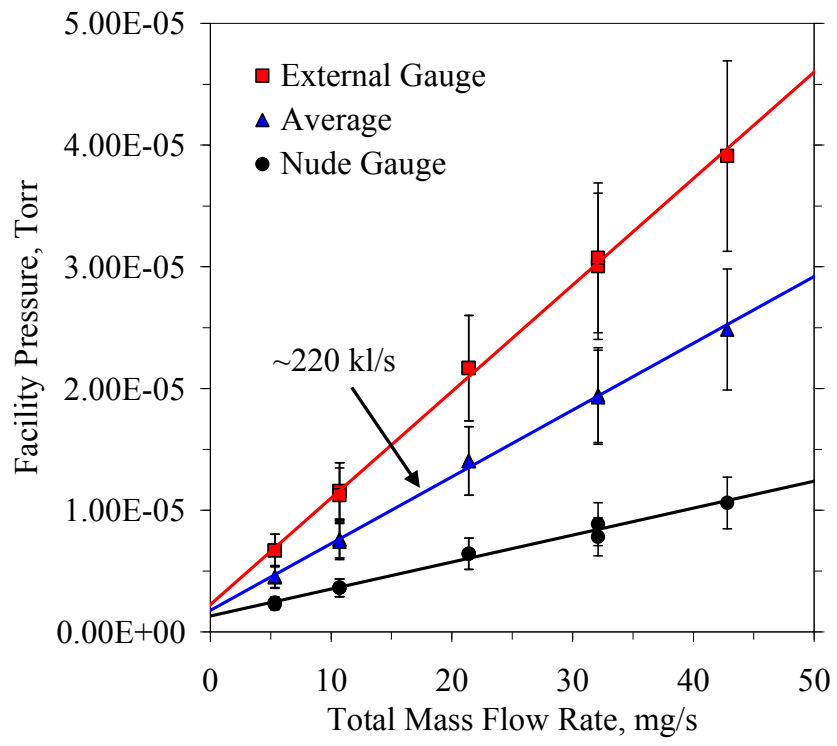

Figure 1. Facility pressure versus operating condition for the LVTF.

\section{B. Hall Thruster}

Experiments were performed using a 6-kW laboratory model Hall thruster that has an approximate throttling range of 100-600 $\mathrm{mN}$ and 1000-3000 s specific impulse [9-12]. The thruster was equipped with a center-mounted $\mathrm{LaB}_{6}$ hollow cathode that was operated at $7 \%$ of the anode mass flow rate. Research-grade xenon propellant (99.999\% pure) was supplied to the anode and cathode by separate commercially-available flow meters and controllers, having an accuracy of $\pm 1 \%$ of full scale. The system was calibrated using a constant volume method including the effects of compressibility [13]. The thruster discharge was sustained by a $100 \mathrm{~kW}$ power supply that provided a maximum output of $1000 \mathrm{~V}$ at $100 \mathrm{~A}$. The thruster was positioned so that it was elevated to chamber centerline, allowing the plume to expand for approximately four meters along the chamber axis.

\section{Nude Faraday Probe}

Two nude Faraday probes were used to measure the local current density at the $\mathrm{E} \times \mathrm{B}$ probe inlet. The Faraday probes were aligned vertically and axially with the entrance orifice of the $\mathrm{E} \times \mathrm{B}$ probe, and offset radially on either side of the $\mathrm{E} \times \mathrm{B}$ inlet by approximately $15.5 \mathrm{~cm}$. Two probes were used to ensure adequate spatial resolution and redundancy. The current density was used to provide a weighting of the local charge-state so that a plume-averaged value could be calculated (see section III.D). The nude Faraday probe collector surface was a $2.31-\mathrm{cm}$ diameter, tungsten-coated, stainless-steel disk. The tungsten coating reduces the secondary electron emission due to the impacts of high-energy ions. To reduce edge effects, the collector was surrounded by a guard ring that was biased to collector potential ensuring that the sheaths overlap. The collector and guard ring were biased at $-15 \mathrm{~V}$ with respect to ground, and the current collected at the probe was measured across a 107.1 $\Omega$ current shunt. The Faraday probes used in this study are well-characterized and are described in more detail in Ref. [14].

\section{E $\times$ B Probe}

An $\mathrm{E} \times \mathrm{B}$ probe, or Wien filter, is a band-pass ion filter that selects ions according to their velocities through the application of crossed electric and magnetic fields $[6,7,15,16]$. Since the velocity of multiply-charged ions in Hall thrusters is proportional to the square root of their charge-state, an $\mathrm{E} \times \mathrm{B}$ probe can be used to discriminate between 
ion species. Analysis of the ion current from the probe characteristic can then be used to compute the ion current fractions. For the results presented here, the analysis followed the methods described in Ref. [7].

Ions that enter the probe must traverse the test section without being deflected in order to be registered by the collector. Collected ions must therefore experience zero net force inside the probe, which can be described by the Lorentz force equation $(F=e Z(E+u B)$ where the electric and magnetic fields are both normal to the ion velocity.

\section{Probe Design}

The E $\times \mathrm{B}$ used in this study was designed by the NASA Glenn Research Center, based on a set of incremental improvements upon the probe used by Hofer in Ref. [17]. The test section was $150 \mathrm{~mm}$ long. The inlet and outlet collimators were $75 \mathrm{~mm}$ long. Both collimating orifices and the inlet orifice were $1.6 \mathrm{~mm}$ in diameter. To reduce the effects of secondary electron emission due to the impacts of high-energy ions on the collector, the collector was shaped as a high aspect ratio tube with a conical end (see Figure 2) and spray coated with tungsten. Tungsten has a relatively low-yield of secondary electrons under xenon bombardment and the collector geometry ensured that any secondary electrons that were emitted were re-collected. The collected current was sent to a picoammeter using a 50 $\Omega$ BNC cable and feed through.

The fixed magnetic field was supplied by two permanent magnets, reaching a peak of $0.16 \mathrm{~T}$ in the center of the probe test section. The magnets were made from a sintered hard ferrite, with a Curie temperature of $730 \mathrm{~K}$, and a rated operating temperature of $530 \mathrm{~K}$. The electric field was supplied by two parallel plates, spaced $9.7 \mathrm{~mm}$ apart, that were biased with a programmable voltage source above and below ground by equal amounts using the circuit in Figure 2a. By splitting the applied voltage between the two plates, the potential on the probe centerline was held approximately constant and remained within a few volts of facility ground.
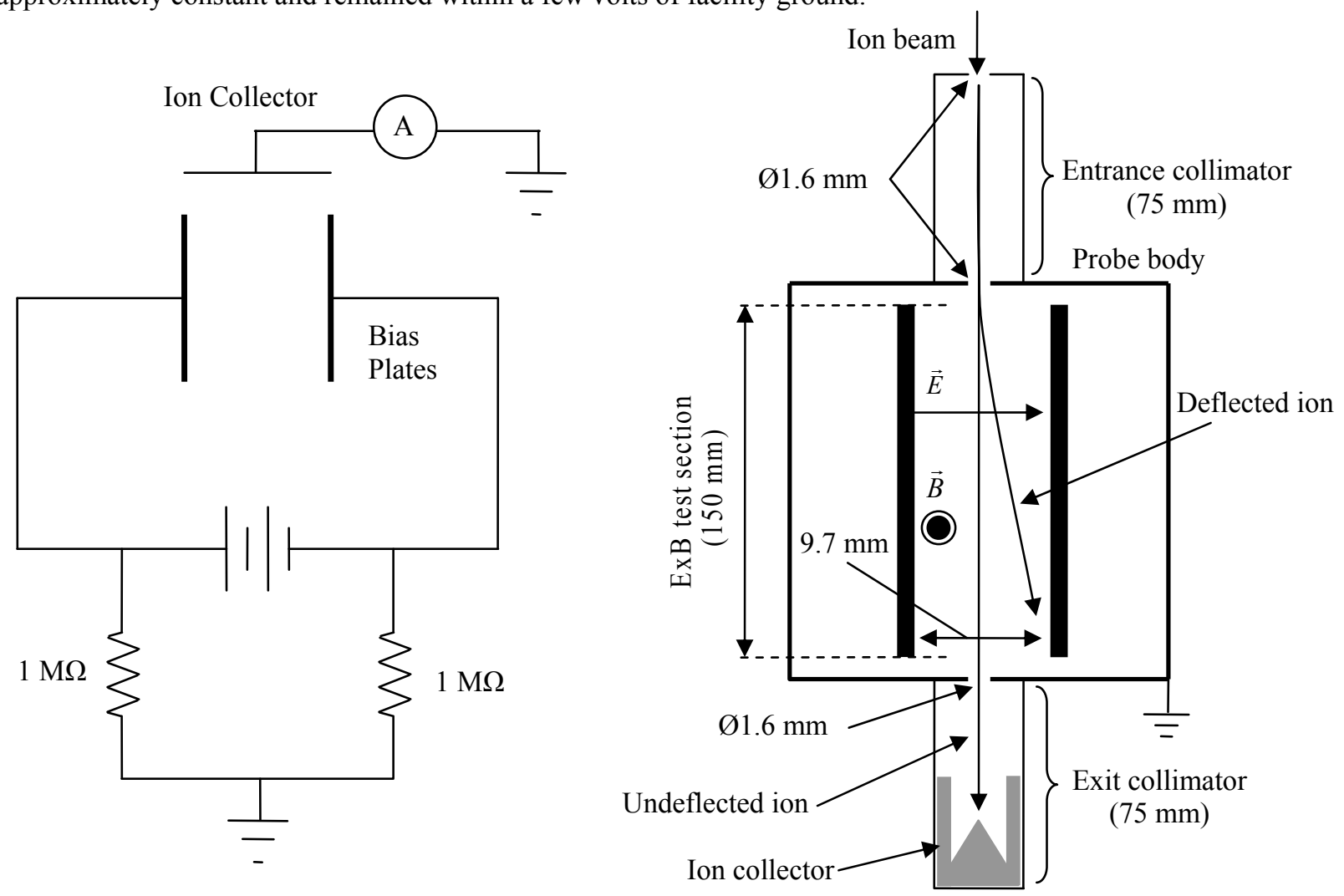

Figure 2. $E \times B$ probe electrical diagram and schematic (not to scale).

During these tests, the electric field was applied from high to low magnitude, allowing the shape of higher charge states (greater than $2^{+}$) to be qualitatively assessed during data collection. To maintain good signal quality throughout testing, the probe body and internal components were connected to facility ground. This prevented charging of internal components that can lead to unrepeatable and unreliable results.

The appropriate inlet orifice was selected by considering the full range of expected current density at the $\mathrm{E} \times \mathrm{B}$ inlet. The peak collected current should be maintained around $10^{-9}$ A to maintain a reasonable signal to noise ratio. 
For these tests, the peak collector current ranged from 3 to $40 \times 10^{-10} \mathrm{~A}$, while the inlet current was $3-30 \times 10^{-6} \mathrm{~A}$ (estimated based on ion current density and inlet diameter). This indicates that the peak current is approximately four orders of magnitude less than the inlet current, a rule of thumb that can be used to estimate the expected range of collector currents for future experiments.

\section{Probe Heating}

To minimize the heat flux to the probe body, the front of the $\mathrm{E} \times \mathrm{B}$ probe was protected with a graphite panel that had a hole cut for the inlet. The plate was connected to the leveling table, and positioned approximately $3 \mathrm{~cm}$ downstream from the probe inlet. The temperature of the probe was measured at the upstream and downstream vertical surfaces with K-type thermocouples embedded in the iron pole pieces. The temperatures measured by these thermocouples throughout the entire experiment are shown in Figure 3. The temperature of the upstream thermocouple was directly proportional to discharge power and appeared to increase linearly with exposure time. The temperature decreased as the probe was moved into the periphery of the plume, indicating that most of the heating was due to heat flux deposited onto the inlet tube and conducted to the upstream surface. The temperature of the downstream thermocouple responded on a longer time-scale, displaying a nearly monotonic increase in temperature throughout the experiment. These trends were taken to indicate that the downstream thermocouple was representative of the bulk probe temperature, while the upstream thermocouple was taken as the instantaneous worst-case temperature.

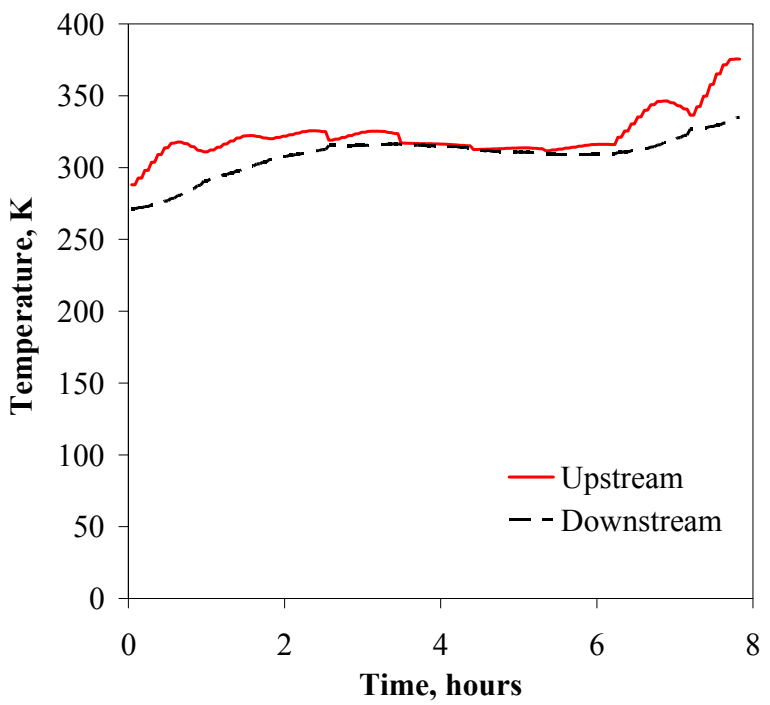

Figure 3. $E \times B$ probe temperature throughout experiment.

The maximum temperature that the magnets reached was between 340 and $380 \mathrm{~K}$, well below the maximum operating temperature of $530 \mathrm{~K}$. However, the magnetic permeability decreases with temperature, causing the peak magnetic field within the probe to decrease throughout the experiment. Since the time scale of the probe temperature change was much longer than the data collection period of individual spectra, the time-dependence of the magnetic field variations were judged to be negligible. For the entire data set, the changes in the magnetic field only affected the electric field necessary to filter each species, which was not a concern since this experiment was not focused on obtaining absolute measurements of the ion energy.

\section{Probe Internal Pressure}

A rise of the pressure internal to the probe due to filling from thruster and facility neutrals is often suspected as a potential cause of corrupted results. To evaluate this potential issue, a brief mass continuity analysis was performed to quantify the pressure change expected while the probe was operating. The pressure inside the probe reaches equilibrium when the flux of incoming ions and neutrals are balanced by the exiting flux of probe neutrals. The entering flux of ions was estimated based on the ion current density at the probe entrance and the neutral fluxes were calculated as random thermal fluxes across the probe vent holes. Using the number density given by the equilibrium probe pressure, the mean free path for an ion-neutral collision within the probe was estimated using the CEX collision cross section of approximately $4 \times 10^{-19} \mathrm{~m}^{2}$. The worst-case inlet flux is encountered at $300 \mathrm{~V}, 30 \mathrm{mg} / \mathrm{s}$ with 
the probe located 8 thruster diameters from the exit plane on thruster centerline. In this case, the mean free path is on the order of $10 \mathrm{~m}$, which is considerably longer than the $\mathrm{E} \times \mathrm{B}$ length of approximately $0.5 \mathrm{~m}$. This analysis indicated that the pressure inside the probe at worst-case conditions caused a negligible amount of particle scattering within the test section.

\section{Spectrum Repeatability}

To confirm proper operation of the probe, and verify that temperature and pressure changes were negligible, six probe spectra were recorded and compared as shown in Figure 4. The probe was in the plume for approximately 12 minutes, and each trace was taken immediately after the previous one had completed. These results show that the probe spectrum is highly repeatable.

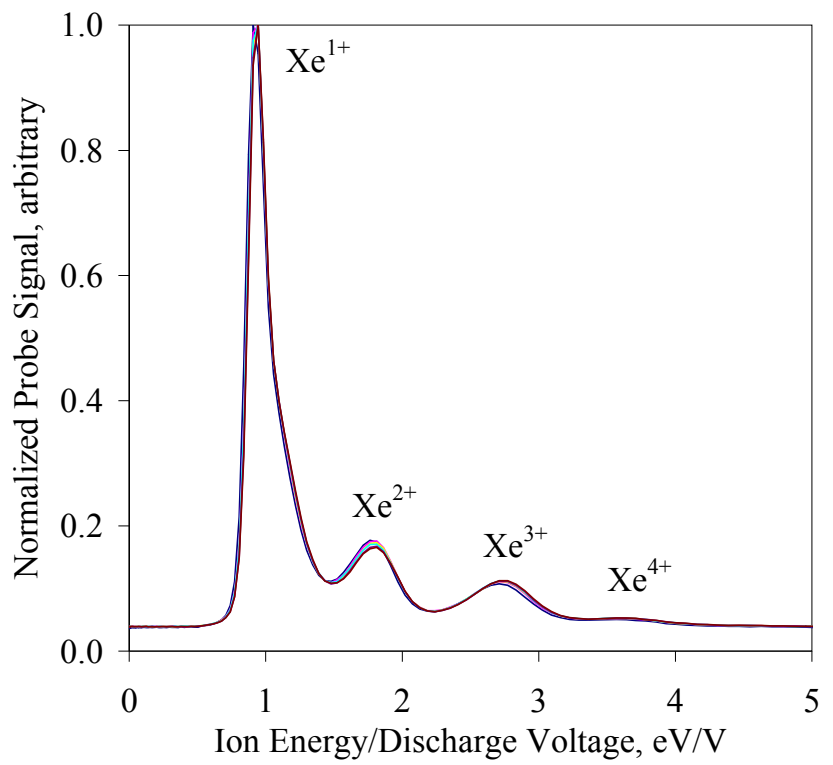

Figure 4. Six $\mathbf{E} \times \mathbf{B}$ probe spectra that demonstrate trace repeatability $\left(300 \mathrm{~V}, 10 \mathrm{mg} / \mathrm{s}\right.$, Theta $=0^{\circ}, Z=12$ thruster diameters).

\section{Positioning System and Alignment}

The $\mathrm{E} \times \mathrm{B}$ probe and two Faraday probes were attached to a probe-leveling table. This assembly was rotated using a rotational stage, and moved radially and axially with $1.5-$ and $0.9-\mathrm{m}$ linear translation stages, respectively. The position uncertainty of the rotational and linear translation stages were conservatively estimated as $0.1^{\circ}$ and $0.1 \mathrm{~mm}$, respectively.

The $\mathrm{E} \times \mathrm{B}$ probe was aligned with the thruster by shining a laser from the rear of the probe (with the collector removed), through the probe inlet, and onto a mirror on the center of the thruster, and back to the probe body. The leveling table was adjusted to correct the vertical alignment and the table angle was adjusted to correct the horizontal alignment. Alignment was considered adequate when the laser returned to within $1 \mathrm{~cm}$ of the probe inlet. The cumulative uncertainty from the alignment of the probe and tables and the positional accuracy of the translation stages resulted in a conservative pointing uncertainty estimate of approximately $\pm 2^{\circ}$.

Ion current density measurements were taken with the Faraday probe pointed at the center of the thruster and with the probe aligned parallel to the thrust axis (i.e., the $\mathrm{z}$ direction). All $\mathrm{E} \times \mathrm{B}$ probe spectra were acquired with the probe table pointed at thruster center, such that the probe was nearly parallel to the local ion current density vector. The validity of this pointing methodology was tested prior to data collection at $300 \mathrm{~V}, 20 \mathrm{mg} / \mathrm{s}$ by varying the probe angle with respect to the thruster and recording the collected current. We consistently found that pointing at thruster center maximized the collected current, which verified that the probe was properly aligned with the local ion current density vector. It is interesting to note that this is equivalent to the plume isotropically expanding from the thruster exit. An example of this alignment test at 0,3 , and $25^{\circ}$ from thruster centerline is shown in Figure 5. Since these measurements were taken manually, there as increased error in each value due to the picoammeter output fluctuation. The error here was conservatively estimated at $2 \%$ of reading, whereas the picoammeter is specified at $0.4 \%$. These results also indicated that the maximum collected current was relatively insensitive to probe alignment 
within $2^{\circ}$ of the isotropic expansion alignment. This was consistent with the approximate probe acceptance angle and pointing accuracy.

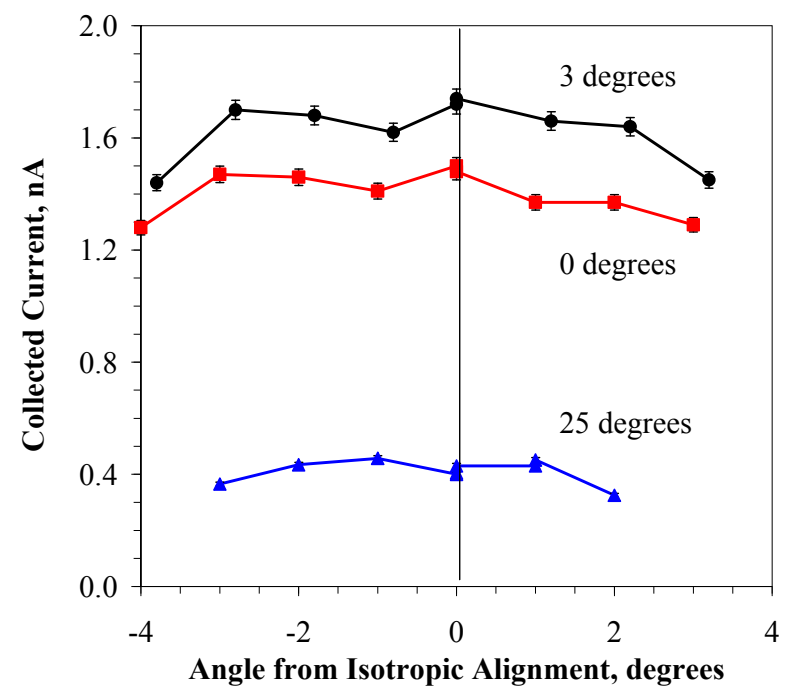

Figure 5. E $\times$ B probe alignment study at 0,3 , and $25^{\circ}$ from thruster centerline $(300 \mathrm{~V}, 20 \mathrm{mg} / \mathrm{s}, \mathrm{Z}=8$ thruster diameters).

A schematic of the data collection methodology from the experiment is shown in Figure 6. Radial profiles from thruster centerline were acquired at several axial distances from the thruster exit plane. At each position, the $\mathrm{E} \times \mathrm{B}$ probe was turned to point at thruster center and then $\mathrm{E} \times \mathrm{B}$ and Faraday probe data were acquired. The probe table was then turned back so that it was parallel to the thrust axis and Faraday probe data were acquired again. The plume was assumed to be axisymmetric, so only one side of the plume was interrogated.

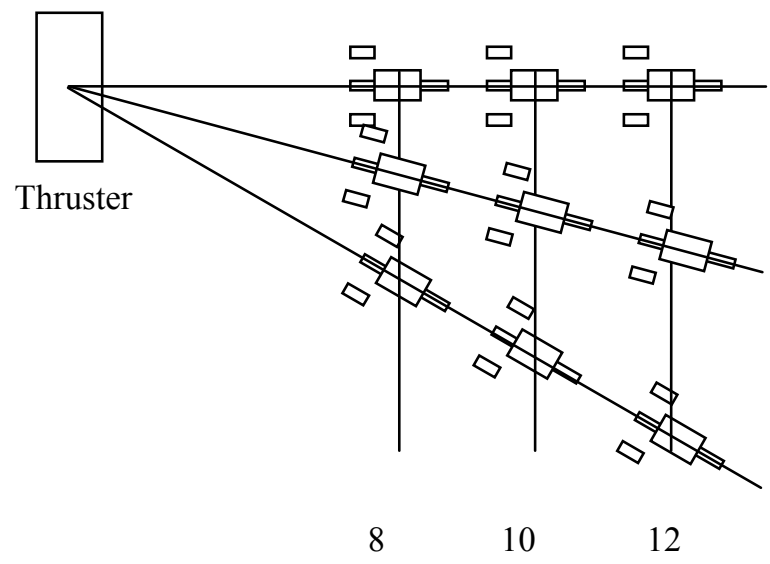

Thruster Diameters

Figure 6. Schematic of the data collection methodology (not to scale).

\section{Spectrum Analysis and Correction Methods}

The method outlined by Shastry, et al. [7] was used to analyze each $\mathrm{E} \times \mathrm{B}$ probe spectrum and determine the current fractions for each ion species. Triangles were fitted to each peak by forming a line between the maximum and half-maximum current values on the higher-energy side of the peak, as this side tends to be less susceptible to collisional broadening and thus is more well-defined. The line, which was extrapolated to zero current, was then reflected across the peak center, and the area of the resulting triangle was taken as an approximate integral of the collected current for the corresponding ion species. The collected current was then corrected for CEX collisions with facility neutrals within the plume using a simple 1-D model which describes the attenuation of beam ions as an exponential falloff with distance and facility backpressure. In order to keep the CEX correction within reasonable 
limits, the facility pressure and probe distance should be set so that the beam attenuation remains below $30 \%$. This corresponds to a requirement of $P Z \leq 2$, where $P$ is the backpressure in units of $10^{-5}$ torr, and $Z$ is the absolute distance between the thruster exit plane and the probe entrance in meters. Errors induced by this method were estimated by varying the integral area, the backpressure, and the relevant CEX cross sections within their respective uncertainty bounds, and noting the corresponding changes in calculated quantities. This analysis method produces a conservative uncertainty in current fractions of $\pm 3 \%$ for $\mathrm{Xe}^{1+}$, and $\pm 20 \%$ for $\mathrm{Xe}^{2+}$ and $\mathrm{Xe}^{3+}$.

\section{Results}

Angularly-resolved $\mathrm{E} \times \mathrm{B}$ probe spectra were acquired at seven operating conditions ranging from approximately 1 to $10 \mathrm{~kW}: 150$ and $300 \mathrm{~V}$ at 10,20, and $30 \mathrm{mg} / \mathrm{s}$, and $600 \mathrm{~V}$ at $10 \mathrm{mg} / \mathrm{s}$. Data were taken at a distance of 8 thruster diameters from the thruster exit plane at radial locations equivalent to $1^{\circ}$ increments from 0 to $5^{\circ}$ and $5^{\circ}$ increments from 5 to $30^{\circ}$ from thruster centerline. At $300 \mathrm{~V}, 20 \mathrm{mg} / \mathrm{s}$, data were also taken at 10 and 12 thruster diameters, allowing probe measurements from $0-25^{\circ}$ and $0-20^{\circ}$, respectively.

The thruster was run for approximately 60 minutes at $300 \mathrm{~V}, 10 \mathrm{mg} / \mathrm{s}$ prior to data collection, and allowed to reach equilibrium for approximately 20 minutes in between each operating condition. During the initial bakeout of the discharge channel ceramic, $\mathrm{Xe}^{4+}$ was not detected in the $\mathrm{E} \times \mathrm{B}$ probe spectra, but were resolvable after approximately 30 minutes of thruster operation. Although $\mathrm{Xe}^{4+}$ was detected for most of the probe traces, its contribution will be neglected in the analysis since its species fraction typically remains $<<1 \%$.

The operating conditions were ordered in increasing power levels, so that the temperature gradient of the probe was always positive. Measurements at near $10 \mathrm{~kW}$ only extend to $20^{\circ}$ due to a thermal failure of the cables used to operate the probe. When the probe assembly was positioned directly in front of the thruster, the discharge current elevation never exceeded $1 \%$.

For the measurements in this experiment, $P Z$ was approximately 1,2 , and 3 at 10,20 , and $30 \mathrm{mg} / \mathrm{s}$, respectively. Since $P Z$ was greater than two, the beam attenuation at $30 \mathrm{mg} / \mathrm{s}$ was greater than $30 \%$ prior to reaching the probe, possibly leading to increased uncertainty in the CEX correction when compared to the 10 and $20 \mathrm{mg} / \mathrm{s}$ data.

\section{A. Current Fractions vs Species Fractions}

The primary function of an $\mathrm{E} \times \mathrm{B}$ probe is to measure the current collected due to each individual ion species within the plume. Analysis of the probe spectra yields the ion current fractions of each ion species given by

$$
\Omega_{i}=\frac{I_{i}}{\sum I_{i}}=\frac{n_{i} Z_{i}^{3 / 2}}{\sum n_{i} Z_{i}^{3 / 2}} .
$$

This paper will focus on the current fractions, however, it should be noted that in the Hall thruster literature the most commonly cited figure of merit are the ion species fractions $[6,15,16]$ given by

$$
\zeta_{i}=\frac{n_{i}}{\sum n_{i}}=\frac{\Omega_{i} / Z_{i}^{3 / 2}}{\sum^{\Omega_{i}} / Z_{i}^{3 / 2}} .
$$

The ion current fractions are used here since: 1) they are based directly from the measured currents, and 2) the current fractions are usually used in performance models (see next section). Equations 1 and 2 can be used to convert between the two representations of the data, described in more detail in Ref. [7].

\section{B. Performance Modeling}

In addition to comparisons of individual current fractions, we considered the combined effect of multiplycharged ions on the thruster performance. The anode efficiency can be decomposed as the product of several utilization efficiencies given by

$$
\eta_{a}=\frac{T^{2}}{2 \dot{m}_{a} P_{d}}=\eta_{q} \eta_{v} \eta_{d} \eta_{b} \eta_{m}
$$

where the charge utilization efficiency is

$$
\eta_{q}=\frac{\left(\sum^{\Omega_{i}} / \sqrt{Z_{i}}\right)^{2}}{\sum^{\Omega_{i}} / Z_{i}},
$$


and the mass utilization efficiency is

$$
\eta_{m}=\frac{m_{x e} I_{D}}{\dot{m}_{a} e} \eta_{b} \sum^{\Omega_{i}} / Z_{i} .
$$

The remaining utilization efficiencies (voltage, divergence, and current) are described in Ref. [3]. The charge utilization describes the net decrease of the anode efficiency due to the presence of multiply-charged ions and is a number close to unity for the current fractions typically found in Hall thrusters. While the charge utilization is weakly affected by multiply-charged ions, their influence can not be neglected because they strongly affect the current utilization $\left(\eta_{b}=I_{i} / I_{d}\right)$ and mass utilization $[16,18]$. Our focus here will be on the mass utilization, which is dependent on the multiply-charged ion content through the $\Sigma(\Omega / Z)$ term. This term is referred to as the mass utilization correction factor for multiply-charged ions, and is represented by the variable $\alpha_{\mathrm{m}}$ throughout the rest of this paper.

Another parameter that is useful in quantifying the effects of multiply-charged ions on thruster performance is the effective charge state defined by

$$
Q=\sum Z_{i} \zeta_{i} .
$$

Larson [4] uses the same description of multiply-charged ions in a functionally analogous performance model to the one described by Hofer [2]. As defined, $Q$ is always greater than unity.

Both $\alpha_{\mathrm{m}}$ and $\mathrm{Q}$ are useful in quantifying the effects of multiply-charged ions on thruster performance, but $\alpha_{\mathrm{m}}$ is preferred in this context since its influence on performance parameters is explicitly defined and has the largest impact on anode efficiency. Both parameters are tabulated in the appendix.

\section{C. $\mathbf{E} \times \mathbf{B}$ Spectra}

In this section, a qualitative comparison of the $\mathrm{E} \times \mathrm{B}$ probe spectra was made for measurements taken on thruster centerline at 8 diameters from the thruster exit plane. The effect of discharge voltage on probe spectra was examined by comparing the results at $10 \mathrm{mg} / \mathrm{s}$ for 150,300 , and $600 \mathrm{~V}$. The effect of mass flow rate was examined by comparing the results from 150 and $300 \mathrm{~V}$ at 10,20 , and $30 \mathrm{mg} / \mathrm{s}$.

\section{Effects of Discharge Voltage}

Figure 7 compares $\mathrm{E} \times \mathrm{B}$ probe spectra, normalized to the current peak for singly-charged xenon ions, at 150,300 , and $600 \mathrm{~V}$ at $10 \mathrm{mg} / \mathrm{s}$. The fraction of $\mathrm{Xe}^{2+}$ and $\mathrm{Xe}^{3+}$ were roughly proportional to discharge voltage, and the peaks appeared to be more distinct as voltage was increased. The spectra had similar peak shapes, but the full-width at half-maximum (FWHM) of each species' distribution increased with voltage. The $150 \mathrm{~V}$ condition did not produce a measureable fraction of $\mathrm{Xe}^{4+}$. However, $\mathrm{Xe}^{4+}$ does appear at 300 and $600 \mathrm{~V}$, although the contribution to the total current is $<<1 \%$.

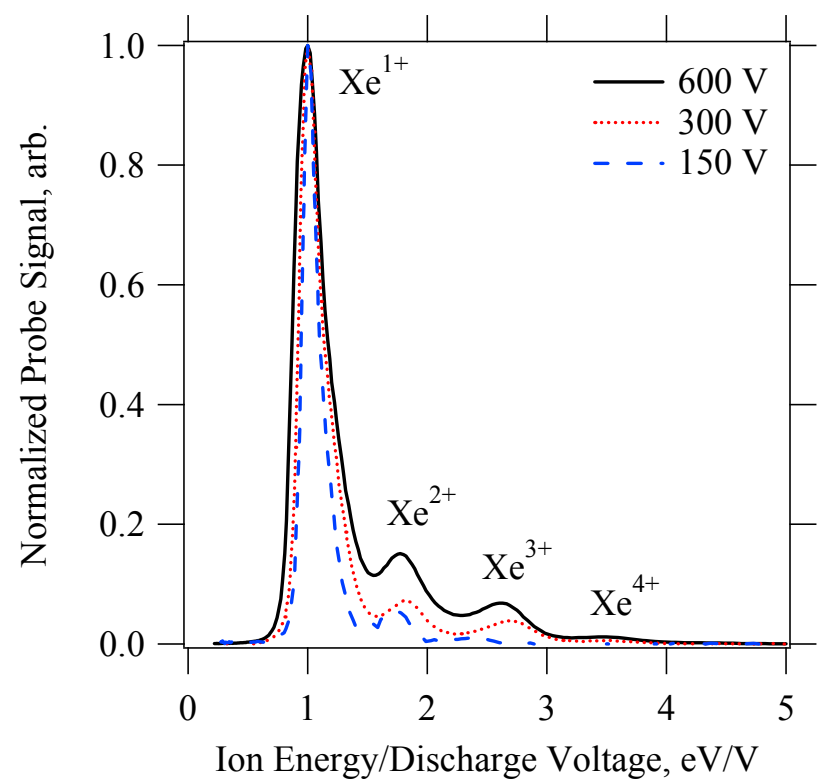

Figure 7. Comparison of $E \times B$ probe spectra at $10 \mathrm{mg} / \mathrm{s}$ at discharge voltages of 150,300 , and $600 \mathrm{~V}(\mathrm{Theta}=$ $0^{\circ}, \mathbf{Z}=\mathbf{8}$ thruster diameters. 


\section{Effects of Mass Flow Rate}

Figure 8 compares $\mathrm{E} \times \mathrm{B}$ probe spectra, normalized to the current peak for singly-charged xenon ions, at 150 and $300 \mathrm{~V}$ for 10,20 , and $30 \mathrm{mg} / \mathrm{s}$. The fraction of $\mathrm{Xe}^{2+}$ and $\mathrm{Xe}^{3+}$ were roughly proportional to anode flow rate. The peaks appeared to be less distinct as flow rate was increased and the $\mathrm{Xe}^{1+}$ peak became wider. At $150 \mathrm{~V}$, the plume divergence angle was much larger than at 300 or $600 \mathrm{~V}$. This considerably decreased the current density at each measurement location, resulting in a decrease in the signal-to-noise ratio from the current collected by the $\mathrm{E} \times \mathrm{B}$ probe. As a result, the $\mathrm{Xe}^{3+}$ peak was almost lost to the noise while $\mathrm{Xe}^{4+}$ was not detected at any of the flow rates.
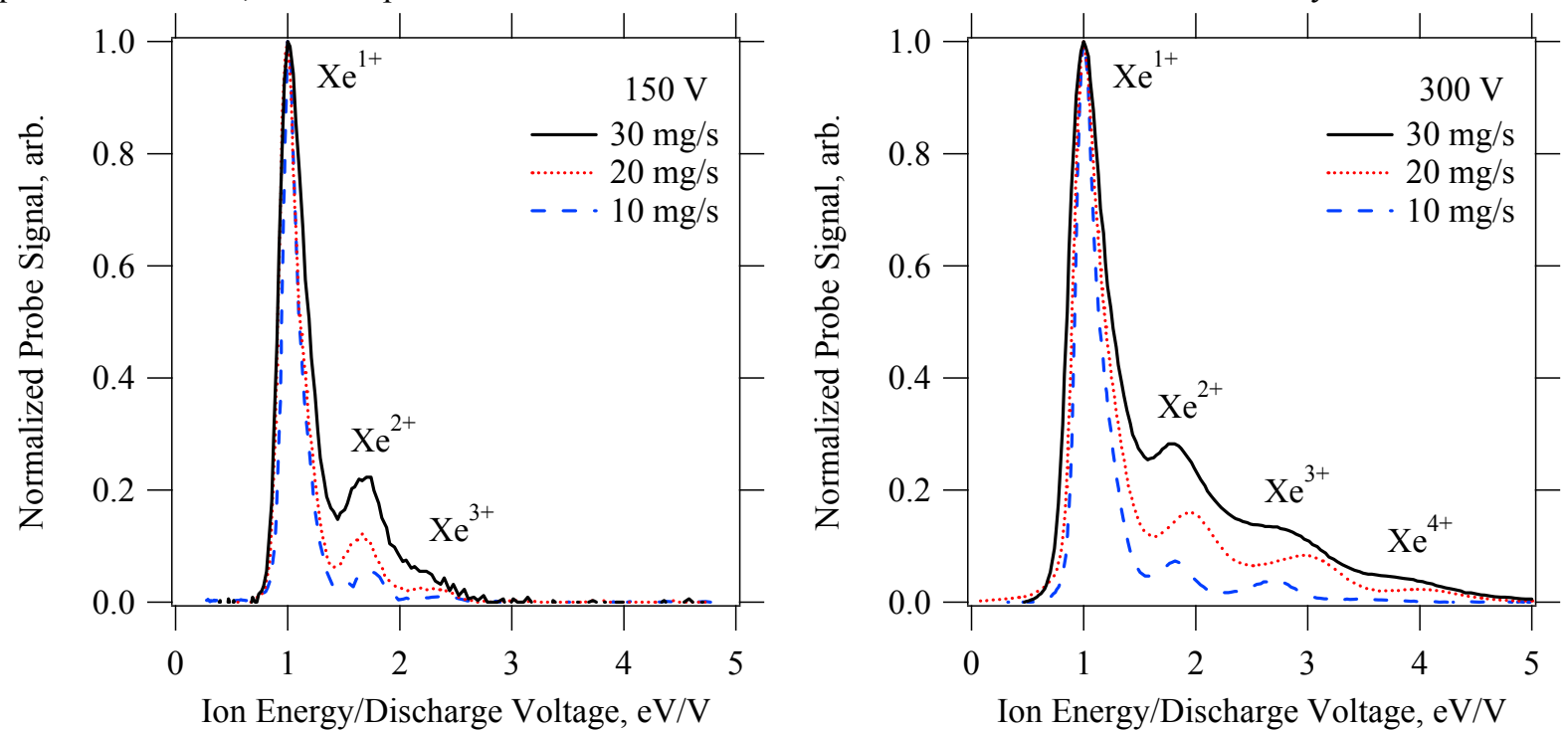

Figure 8. Comparison of $E \times B$ probe spectra at 10,20 , and $30 \mathrm{mg} / \mathrm{s}$ at a) $150 \mathrm{~V}$, and b) $300 \mathrm{~V}$ (Theta $=0^{\circ}, Z=$ 8 thruster diameters.

\section{Effects of Angle}

$\mathrm{E} \times \mathrm{B}$ probe spectra, normalized to the current peak for $\mathrm{Xe}^{1+}$ xenon ions, are presented in Figure 9 from 0 to $25^{\circ}$ for $300 \mathrm{~V}, 20 \mathrm{mg} / \mathrm{s}$ at 8 thruster diameters. The results in Figure $9 \mathrm{a}$, indicated that the peak height of $\mathrm{Xe}^{2+}$ and $\mathrm{Xe}^{3+}$ increased with increasing angle from centerline. Conversely, the data in Figure $9 \mathrm{~b}$ showed that the peak heights went down for angles beyond $10^{\circ}$. However, the current fraction of multiply-charged ions still increased with angle from centerline after accounting for the peak height and peak width for each species, and the loss of beam ions due to CEX collisions. The CEX correction is especially important for the angular comparisons since each angle had a longer path length.
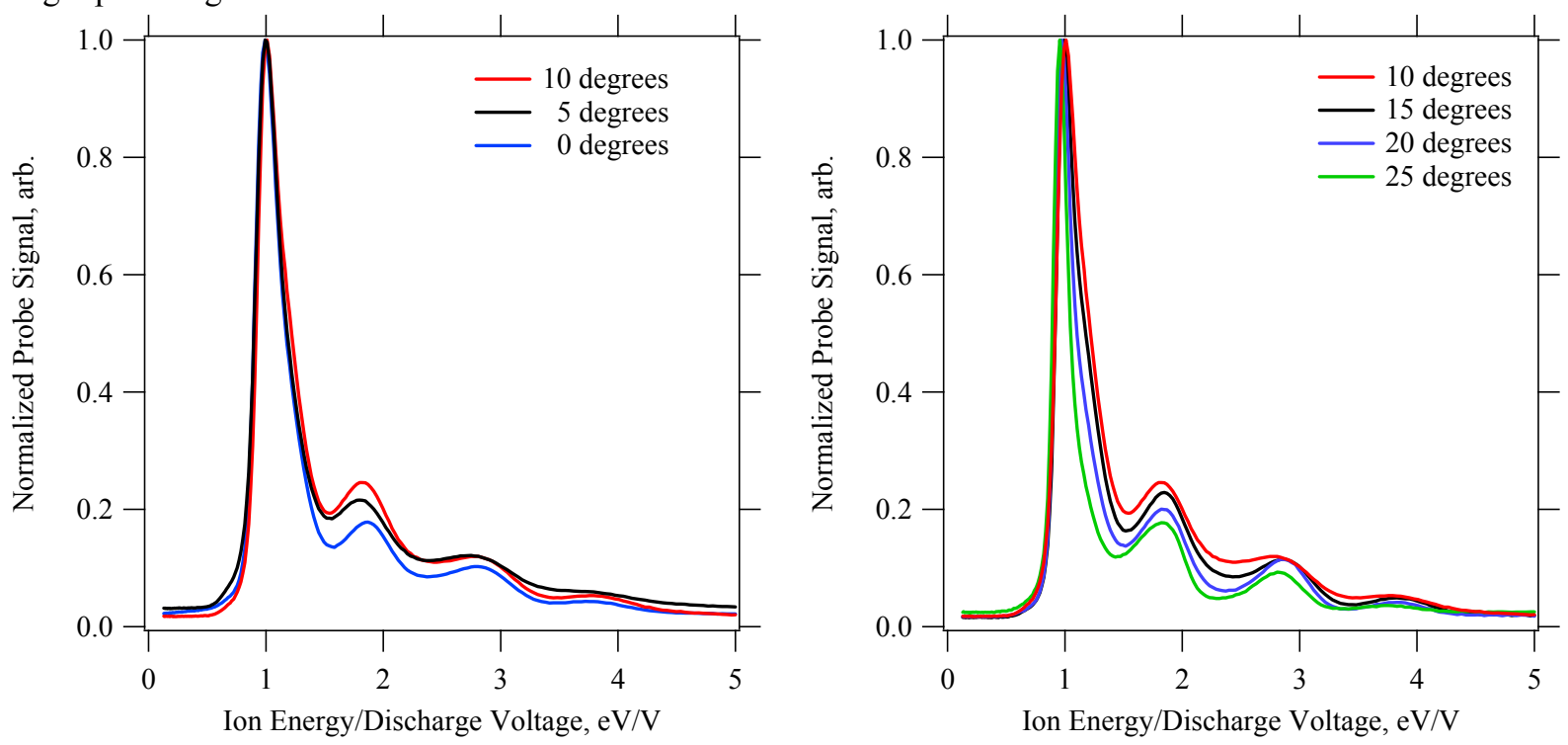

Figure 9. E $\times \mathbf{B}$ probe spectra at $0-25^{\circ}$ from thruster centerline $(300 \mathrm{~V}, 20 \mathrm{mg} / \mathrm{s}, \mathrm{Z}=8$ thruster diameters). 


\section{Determining Plume-Averaged Ion Current Fractions}

Ion current density measurements recorded with the probe axially aligned (face parallel to the thruster exit plane) were used to determine the plume-averaged ion current fractions. After analyzing the probe spectra to yield the local ion current fraction of each species, the local current density was used to weight the current fraction so that a plumeaveraged value could be determined according to

$$
\Omega_{i, \text { vvg }}=\frac{\int_{0}^{R} \Omega_{i, l o c} j(R) R d R}{\int_{0}^{R} j(R) R d R} .
$$

The radial integration was necessary since $\mathrm{E} \times \mathrm{B}$ data were taken along a radial path.

The thruster used in this study had a plume-divergence half angle that was approximately $40-50^{\circ}$. Ideally, data would be captured from 0 to $50^{\circ}$, but translation stage limitations only allowed measurements to $30^{\circ}$. Although data were not collected throughout the entire plume, the species fraction variations captured within the $30^{\circ}$ cone were sufficient to adequately characterize the plume-averaged current fractions due to the rapid decrease of the current density. This was shown by the current density plot in Figure 10 that highlights the locations where $\mathrm{E} \times \mathrm{B}$ data were taken. These data were taken in a previous study from 0 to $90^{\circ}$ on a $1-\mathrm{m}$ probe arm with a rotational stage that was centered on the thruster exit plane. This comparison indicated that the current density dropped by approximately two orders of magnitude from centerline to $30^{\circ}$. Additional species fraction data beyond $30^{\circ}$ would be useful for this analysis, but their contribution to the plume-averaged current fractions are negligible.

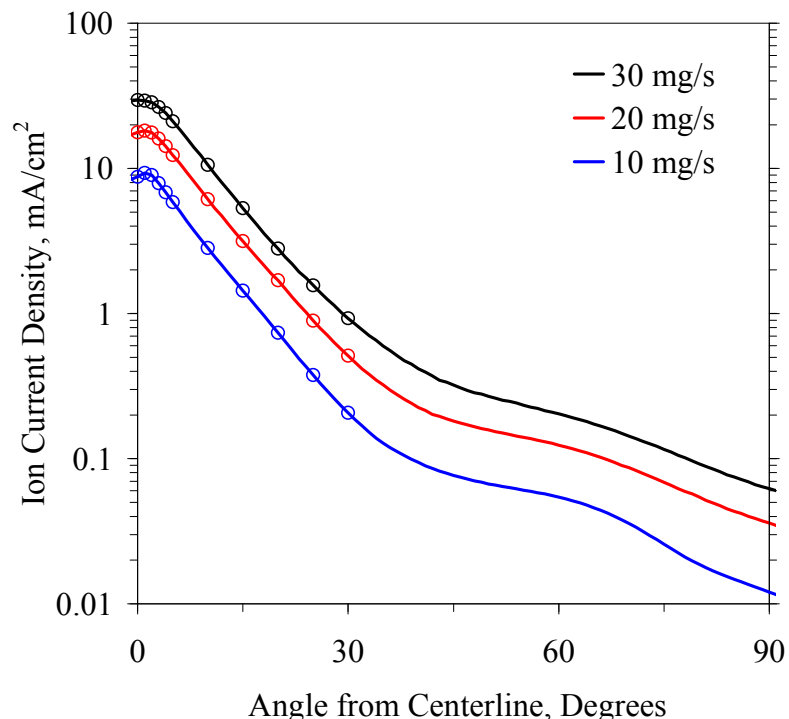

Figure 10. Ion current density from 0 to $90^{\circ}$, showing $E \times B$ data collection locations.

Ion current density profiles for each operating condition are shown in Figure 11a. When normalized (not shown) the profiles show a self-similar characteristic for each discharge voltage; In particular, the normalized current density measurements at 10,20 , and $30 \mathrm{mg} / \mathrm{s}$ lie on top of each other at 150 and $300 \mathrm{~V}$, indicating that the plume structure (i.e., divergence) remained approximately constant as power was increased at constant discharge voltage. This characteristic was important for the corrections applied for CEX collisions since it ensured that facility effects were not dominating the plume-averaging technique at higher flow rates. The data in Figure 11a also indicated that the plume divergence decreased with increasing discharge voltage. Figure $11 \mathrm{~b}$ shows the ion current density at three axial locations $(8,10,12$ thruster diameters). 

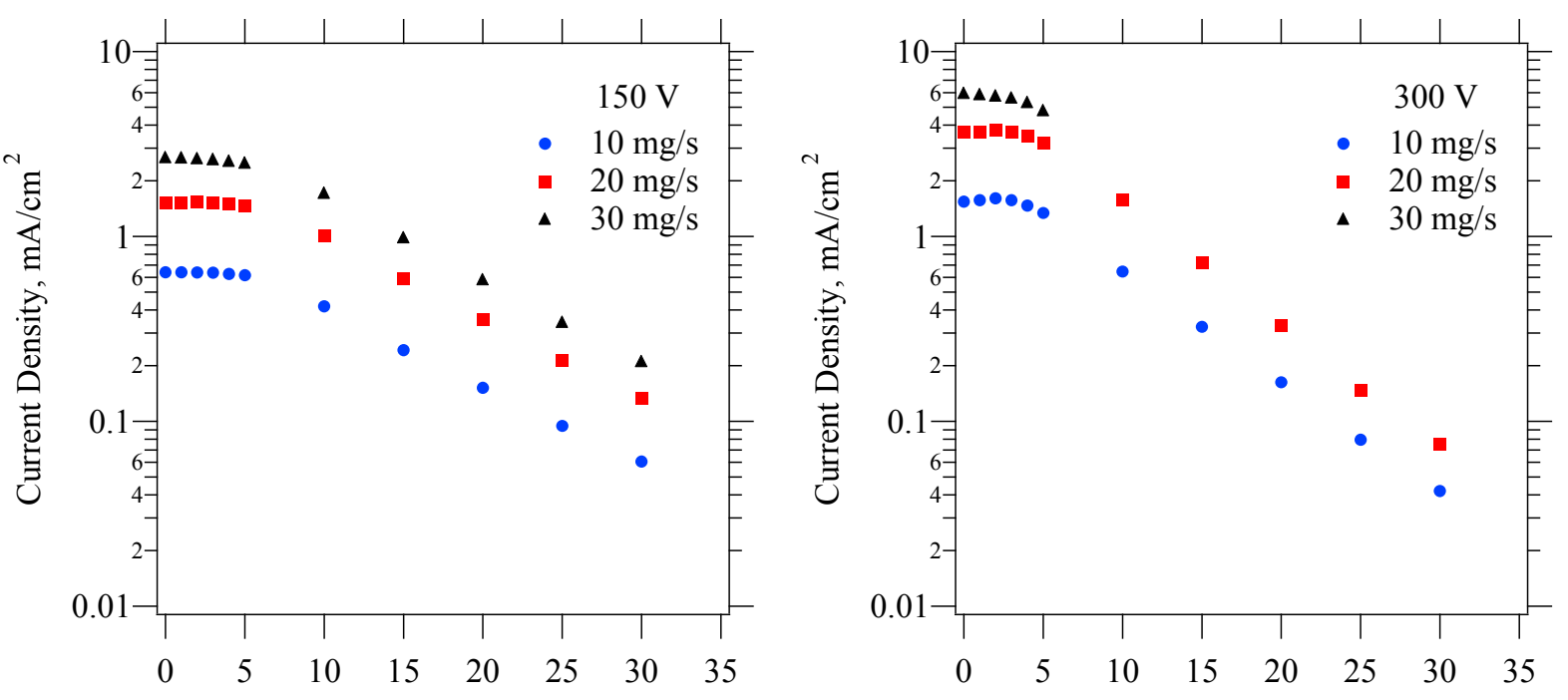

Angle from Centerline, Degrees
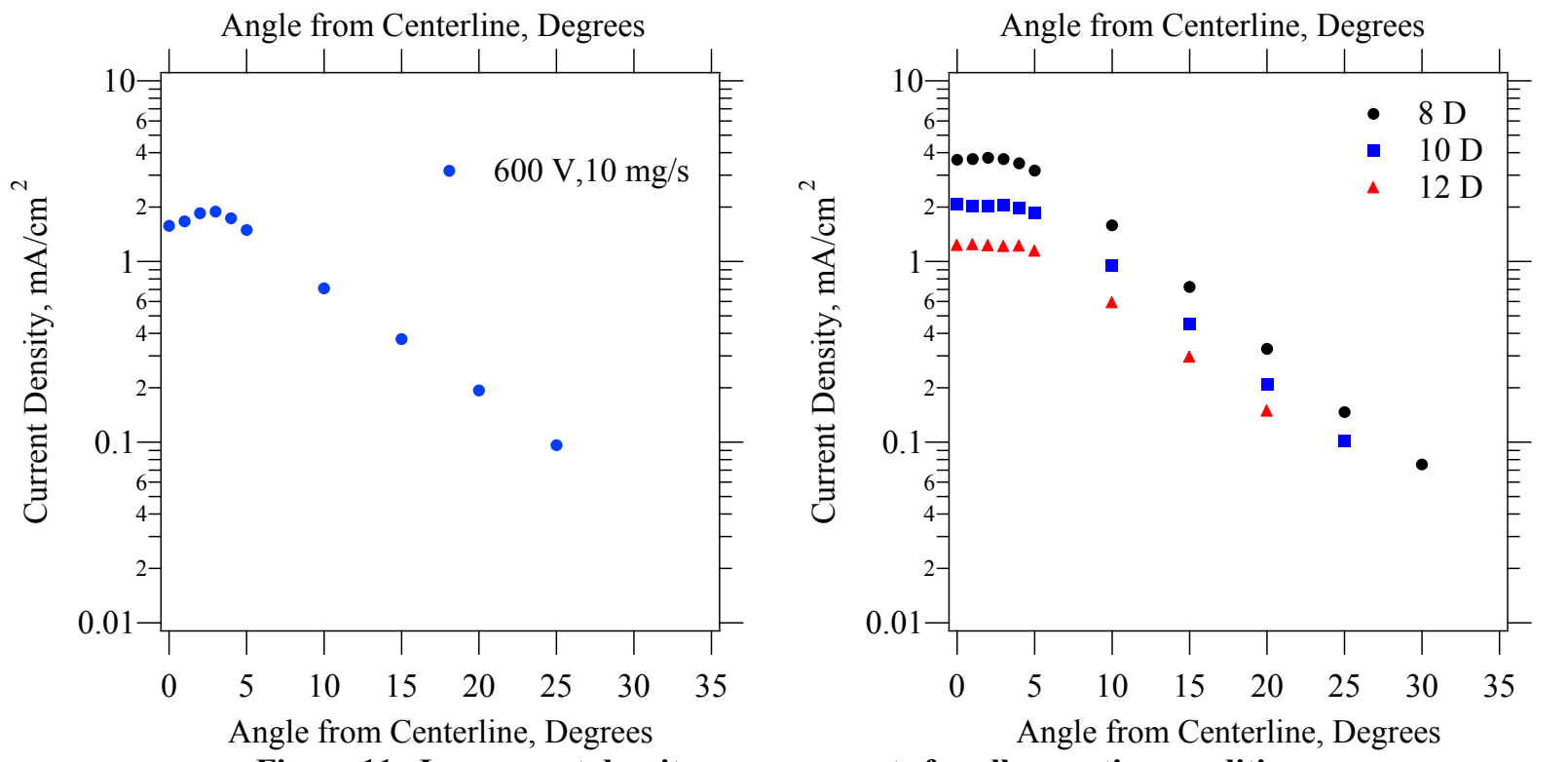

Figure 11. Ion current density measurements for all operating conditions.

\section{E. Angular E $\times \mathbf{B}$ Measurements at 8 Thruster Diameters}

1. $300 \mathrm{~V}, 10,20,30 \mathrm{mg} / \mathrm{s}$

Uncorrected (open marker) and CEX corrected (solid marker) current fraction data are shown in Figure 12a from 0 to $30^{\circ}$ for $300 \mathrm{~V}, 10,20$, and $30 \mathrm{mg} / \mathrm{s}$ at 8 thruster diameters. The current fraction of $\mathrm{Xe}^{3+}$ remained approximately constant at all angles, with values of 3,7 , and $8 \%$ at 10,20 , and $30 \mathrm{mg} / \mathrm{s}$, respectively. These data indicated that the plume was characterized by a monotonically increasing fraction of $\mathrm{Xe}^{2+}$ with angle that was consistent with the monotonic decrease in $\mathrm{Xe}^{1+}$ fraction. This plume structure and the drastic decrease of the $\mathrm{Xe}^{1+}$ fraction at $25^{\circ}$ was consistent with results reported in Refs. $[5,6]$. The existence of a higher fraction of $\mathrm{Xe}^{2+}$ at large angles from centerline was consistent with the hypothesis that $\mathrm{Xe}^{2+}$ were created further downstream than $\mathrm{Xe}^{1+}$, resulting in a larger divergence. The higher divergence angle of $\mathrm{Xe}^{2+}$ was reproduced in plasma simulations of the SPT-100 and BPT-4000 [19].

After the current fractions were corrected for the effects of CEX collisions, the local $\alpha_{\mathrm{m}}$ was calculated at each location so that the effects of multiply-charged ions could be examined in a single parameter. The uncorrected (open marker) and corrected (solid marker) values of $\alpha_{\mathrm{m}}$ from 0 to $30^{\circ}$ are shown in Figure $12 \mathrm{~b} . \alpha_{\mathrm{m}}$ decreases from 0 to $5^{\circ}$

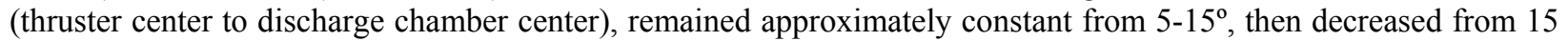
to $30^{\circ}$. These trends were consistent with the data reported in Refs. $[5,6]$. The relative change between the raw and 
CEX corrected $\alpha_{\mathrm{m}}$ was 1,4 , and $5 \%$ at 10,20 , and $30 \mathrm{mg} / \mathrm{s}$. The increased correction at higher flow rate was directly related to the CEX correction dependence on facility pressure.
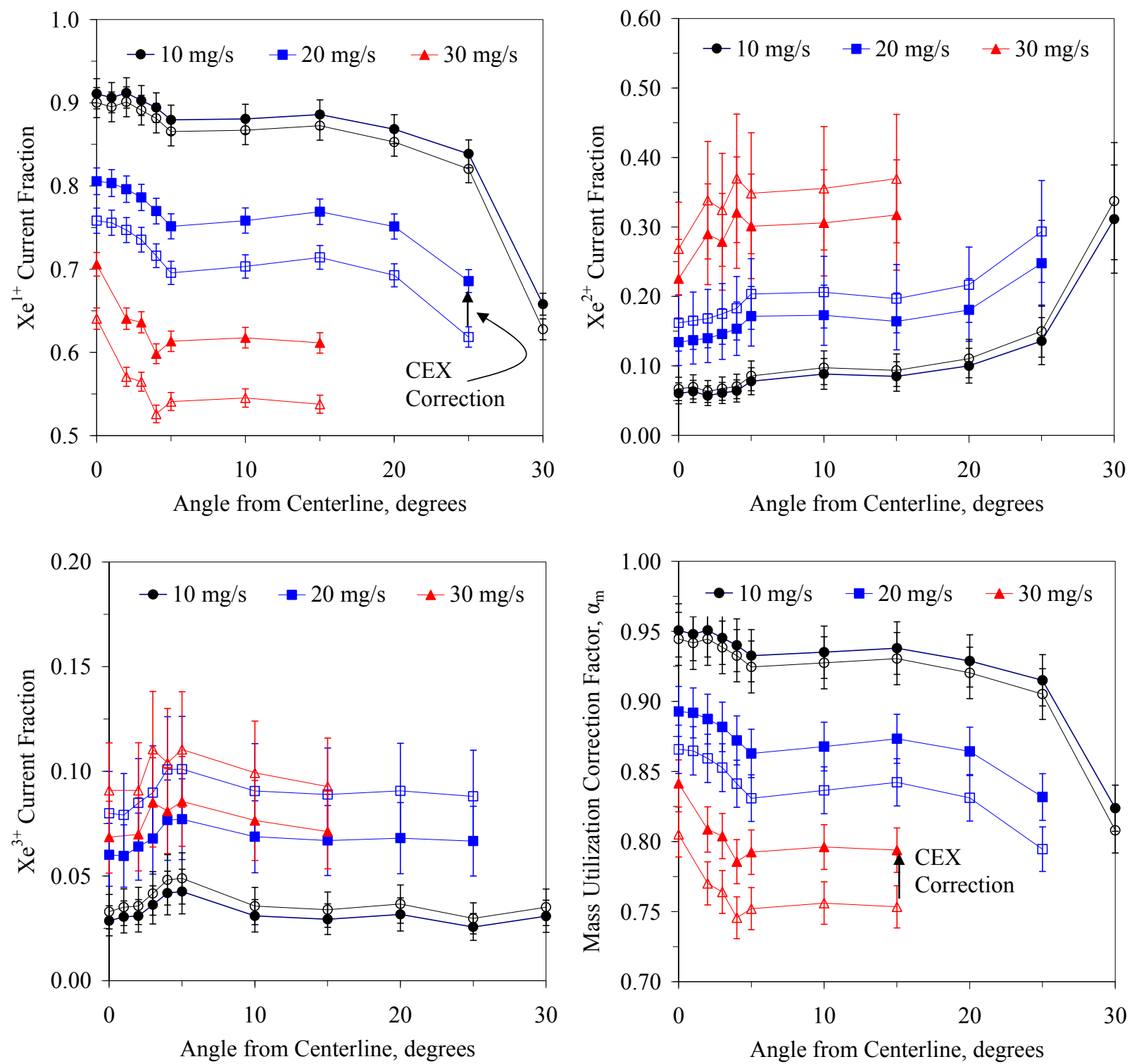

Figure 12. Ion current fractions and $\alpha_{m}$ for $300 \mathrm{~V}, 10,20$, and $30 \mathrm{mg} / \mathrm{s}(\mathrm{Z}=8$ thruster diameters). Open markers are uncorrected data, solid markers have been corrected for CEX.

2. $150 \mathrm{~V}, 10,20,30 \mathrm{mg} / \mathrm{s}$

Uncorrected (open marker) and CEX corrected (solid marker) current fractions and $\alpha_{\mathrm{m}}$ are shown in Figure 13 for angles from 0 to $30^{\circ}$ for $150 \mathrm{~V}, 10,20$, and $30 \mathrm{mg} / \mathrm{s}$ at 8 thruster diameters. The current fractions were relatively constant at all angles, with values near $0.90,0.85$, and 0.77 for $\mathrm{Xe}^{1+}, 0.07,0.11$, and 0.18 for $\mathrm{Xe}^{2+}$, and $0.02,0.03$, and 0.05 for $\mathrm{Xe}^{3+}$, at 10,20 , and $30 \mathrm{mg} / \mathrm{s}$, respectively. The decrease in $\alpha_{\mathrm{m}}$ with increased angle from centerline was significantly less pronounced at $150 \mathrm{~V}$ than at $300 \mathrm{~V}$. This was attributed to the increased plume divergence that resulted in a more uniform distribution of all ion species throughout the measurement domain. 

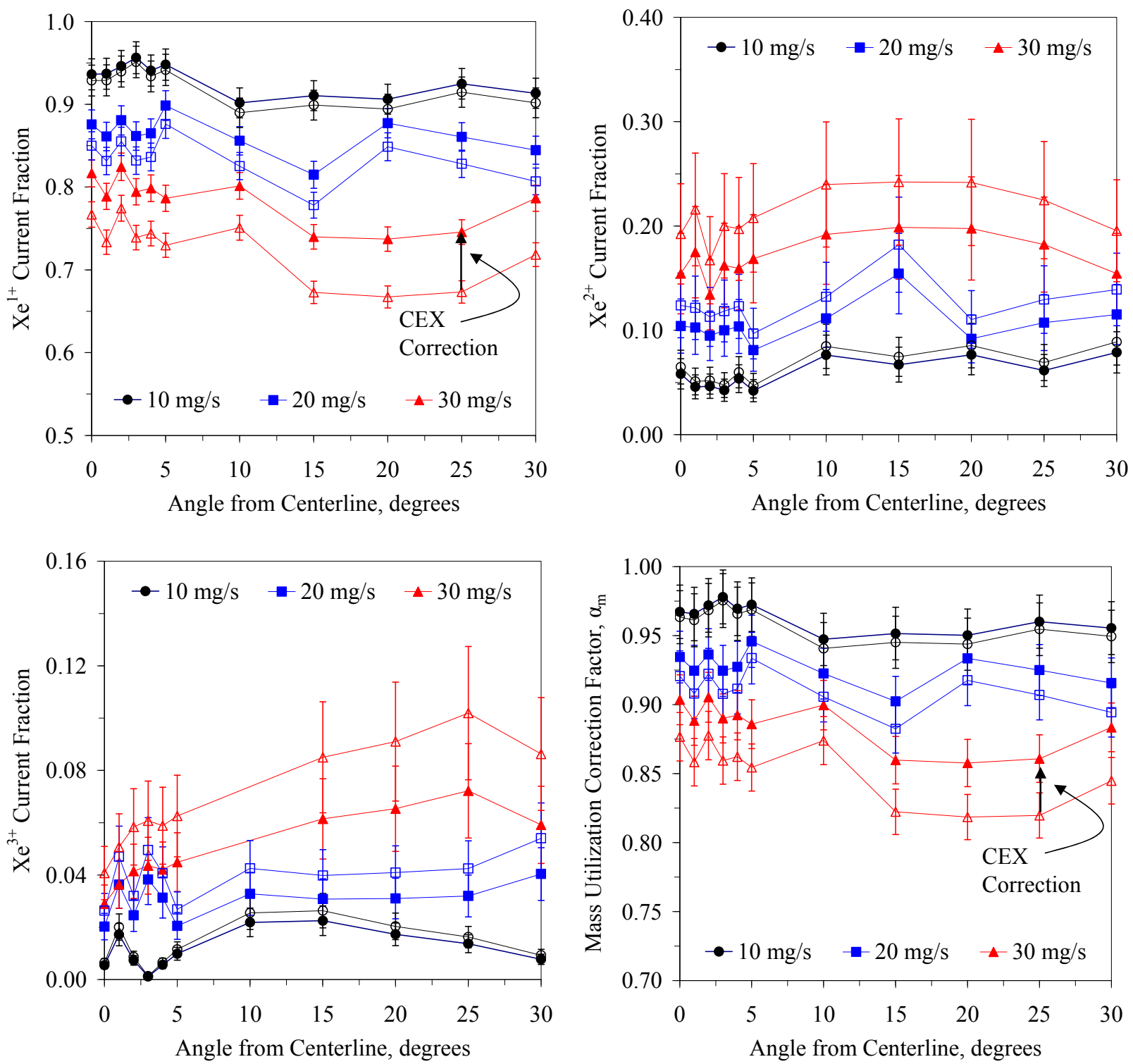

Figure 13. Ion current fractions and $\alpha_{\mathrm{m}}$ for $150 \mathrm{~V}, 10,20$, and $30 \mathrm{mg} / \mathrm{s}(\mathrm{Z}=8$ thruster diameters). Open markers are uncorrected data, solid markers have been corrected for CEX.

3. $600 \mathrm{~V}, 10 \mathrm{mg} / \mathrm{s}$

The ion current fractions and $\alpha_{\mathrm{m}}$ from 0 to $15^{\circ}$ for the $600 \mathrm{~V}, 10 \mathrm{mg} / \mathrm{s}$ operating condition are shown in Figure 14, following the same general trend described for the 150 and $300 \mathrm{~V}$ data. However, the sudden decrease in the fraction of $\mathrm{Xe}^{1+}$ occurred at $10^{\circ}$, much earlier than the $25^{\circ}$ noted at $300 \mathrm{~V}$. The probe traces became difficult to analyze accurately after $15^{\circ}$, which was attributed to decreased beam divergence. The fraction of Xe $\mathrm{e}^{3+}$ increases monotonically with angle from centerline, varying from a minimum of $5 \%$ to maximum of $7 \%$. 

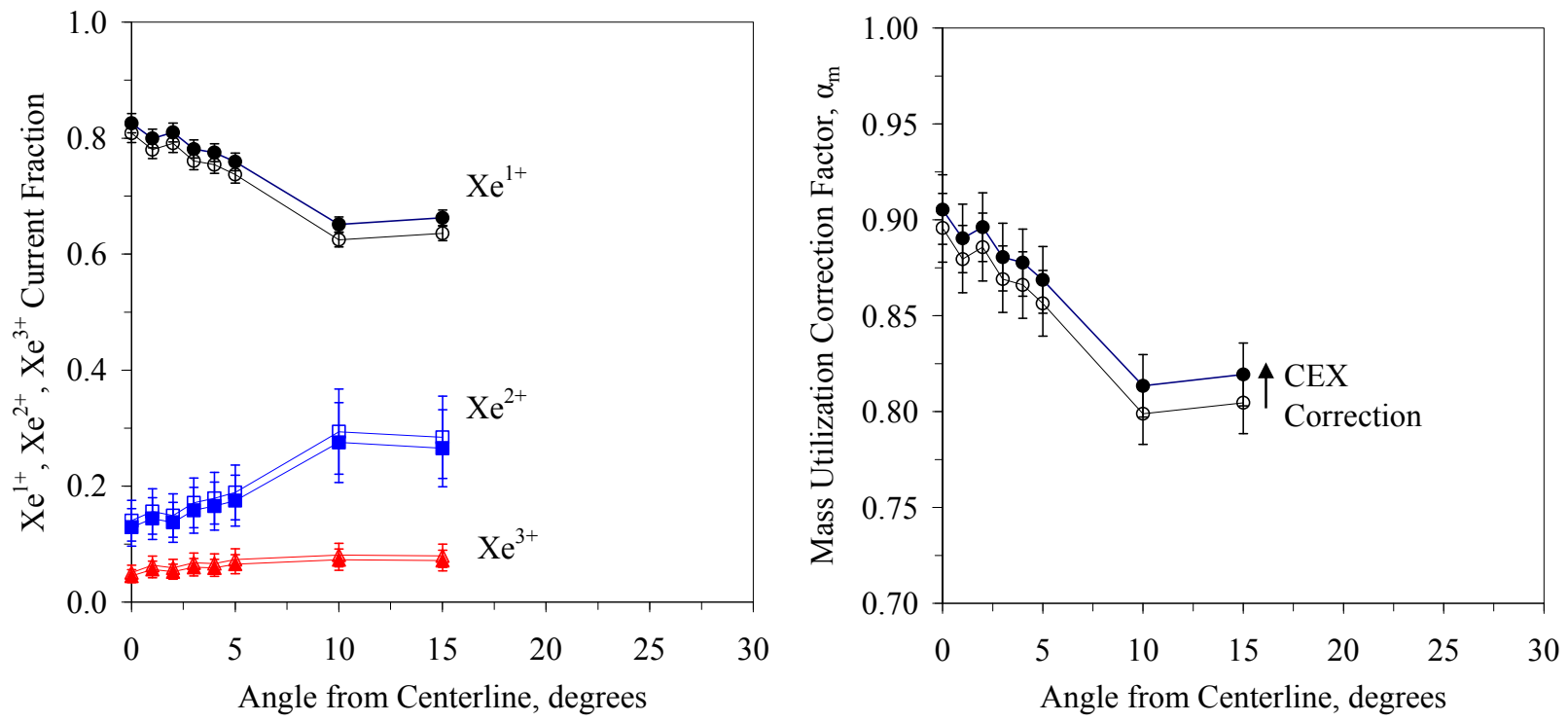

Figure 14. Ion current fractions and $\alpha_{m}$ for $600 \mathrm{~V}, 10 \mathrm{mg} / \mathrm{s}(Z=8$ thruster diameters $)$. Open markers are uncorrected data, solid markers have been corrected for CEX.

\section{F. Angular E $\times$ B Measurements at 8, 10, and 12 Thruster Diameters $-300 \mathrm{~V}, 20 \mathrm{mg} / \mathrm{s}$}

To evaluate the validity of the CEX correction method described by Shastry, et al. in Ref. [7] and investigate the influence of probe distance from the thruster, $\mathrm{E} \times \mathrm{B}$ measurements were taken at 8,10 , and 12 thruster diameters from the thruster exit plane at $300 \mathrm{~V}, 20 \mathrm{mg} / \mathrm{s}$. If the CEX correction was applied properly, the ion current fractions, and hence $\alpha_{\mathrm{m}}$, at each angle should be consistent at each axial distance from the thruster. The angular variation of $\mathrm{Xe}^{1+}$ and $\mathrm{Xe}^{2+}$ at each angle is shown in Figure 15a. The plume-averaged current fractions computed from the data shown in Figure 15a for $\mathrm{Xe}^{1+}$ were $0.75,0.76$, and 0.77 at 8,10 , and 12 diameters, respectively. The plume-averaged current fractions of $\mathrm{Xe}^{2+}$ were $0.18,0.17$, and 0.16 at the three axial locations, and $\mathrm{Xe}^{3+}$ was constant at 0.07 . The corresponding angular variation of $\alpha_{\mathrm{m}}$ at each angle is shown in Figure 15b. The plume-averaged $\alpha_{\mathrm{m}}$ computed from the data shown in Figure $15 \mathrm{~b}$ was $0.863,0.867$, and 0.871 , at 8,10 , and 12 diameters, respectively. The slight increase in the current fraction of $\mathrm{Xe}^{1+}$, and hence $\alpha_{\mathrm{m}}$, was expected since one less angle was sampled at each downstream location. Thus, within an accuracy of \pm 0.005 , the CEX correction method proposed successfully corrected for the loss of main beam ions. This result provides confidence that the CEX correction method accurately models the ion content at the exit plane of the thruster, which is needed for the performance models described previously. 
a)

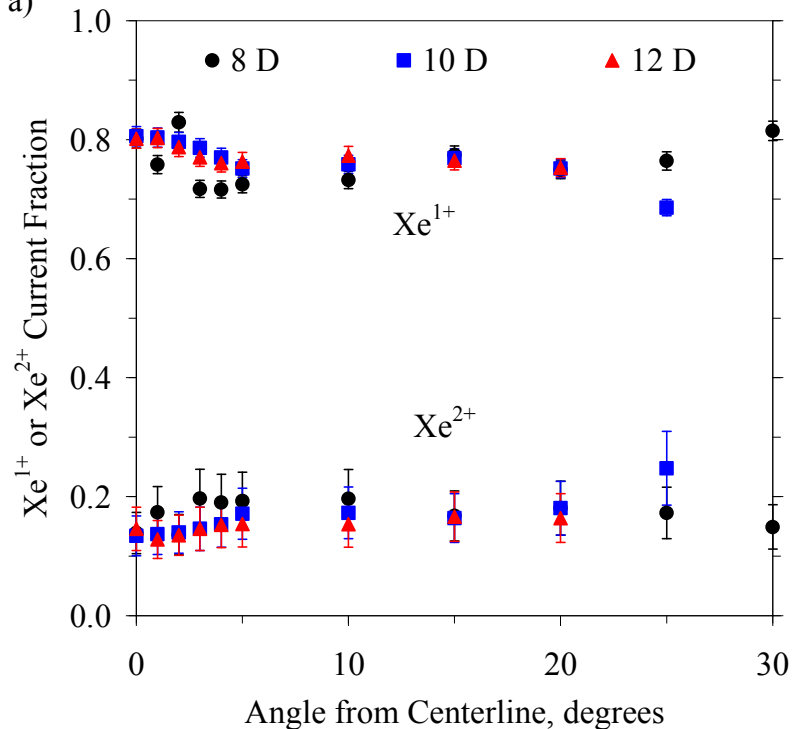

b)

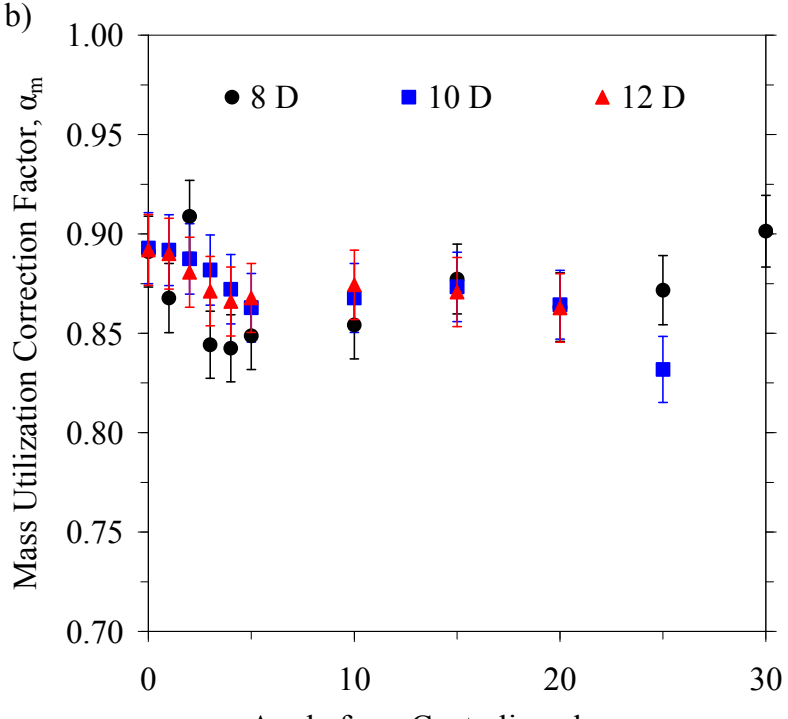

Angle from Centerline, degrees

Figure 15. $\mathrm{Xe}^{1+}$ and $\mathrm{Xe}^{2+}$ ion current fractions and $\alpha_{\mathrm{m}}$ at all angles for each axial distance $(300 \mathrm{~V}, 20 \mathrm{mg} / \mathrm{s}, \mathrm{Z}$ $=8,10,12$ thruster diameters).

\section{Discussion}

In this section, the dependence of thruster operating conditions on the plume-averaged quantities are discussed. We also compared our results with those taken at JPL at similar thruster operating conditions, and HPHall plasma simulations.

\section{A. Influence of Thruster Operating Condition on Plume-Averaged Quantities}

The variation of $\alpha_{\mathrm{m}}$ with both discharge voltage and anode flow rate is shown in Figure 16a. $\alpha_{\mathrm{m}}$ decreased linearly with flow rate at 150 and $300 \mathrm{~V}$, and $\alpha_{\mathrm{m}}$ decreased monotonically with increased discharge voltage. The increasing fraction of multiply-charged ions (decreased $\alpha_{\mathrm{m}}$ ) with discharge voltage was related to the increase in the electron temperature due to Joule heating. Numerous Hall thruster experiments have shown that the maximum electron temperature is approximately $7-14 \%$ of the discharge voltage [20-24]. Increases similar to those reported here of the multiply-charged ion population with discharge voltage were reported by Hofer $[16,17]$ for discharge voltages ranging from 300 to $900 \mathrm{~V}$.

The increased fraction of multiply-charged ions (decreased $\alpha_{m}$ ) with anode mass flow rate was explained by considering the ion production rates. Considering only singly- and doubly-charged ions (since these species dominate the total ion generation rate), the $\mathrm{Xe}^{2+}-$ to- $\mathrm{Xe}^{1+}$ ion production rate ratio is given by

$$
\frac{\dot{n}_{i}^{2+}}{\dot{n}_{i}^{+}}=\frac{\dot{n}_{i}^{0 \rightarrow 2+}+\dot{n}_{i}^{1 \rightarrow 2+}}{\dot{n}_{i}^{0 \rightarrow 1+}}=\frac{\alpha\left(T_{e}\right)^{0 \rightarrow 2+} n_{n} n_{e}}{\alpha\left(T_{e}\right)^{0 \rightarrow 1+} n_{n} n_{e}}+\frac{\alpha\left(T_{e}\right)^{1+\rightarrow 2+} n_{i}^{+} n_{e}}{\alpha\left(T_{e}\right)^{0 \rightarrow 1+} n_{n} n_{e}},
$$

where $n_{n}$ is the neutral density, $n_{e}$ is the plasma density, and the terms $\alpha\left(T_{e}\right)^{0 \rightarrow 1+}, \alpha\left(T_{e}\right)^{0 \rightarrow 2+}$, and $\alpha\left(T_{e}\right)^{1+\rightarrow 2+}$ are the electron temperature dependent ionization rate parameters for the creation of singly- and doubly-charged ions from neutrals and singly-charged ions, respectively [18]. To analyze the dependency of Eqn. 8, results from HPHall plasma simulations were used and tabulated in Table 1. These simulations, which are discussed further below, captured the increase in the fraction of $\mathrm{Xe}^{2+}$ ions with anode flow rate that was measured in the experiment. As shown in the table, the variation in Eqn. 8 with anode flow rate was due to the increase of the second term on the right-hand-side (RHS) of Eqn. 8. This term is the ratio of the ionization of $\mathrm{Xe}^{1+}$ to the ionization of neutral Xe. Further analysis of the second term shows that changes in this ratio were driven by the increased fraction of $\mathrm{Xe}^{1+}$ ions relative to neutrals (shown as the last row in Table 1). These results indicated that as the anode flow rate increased, the increase in the density of singly-charged ions increased the ionization of $\mathrm{Xe}^{1+}$ such that the fraction of $\mathrm{Xe}^{2+}$ comprising the total ion current increased with anode flow rate. 
Table 1: Maximum values of each of the terms in Eqn. 8, derived from HPHall simulations.

\begin{tabular}{lccc}
\hline \hline & $10 \mathrm{mg} / \mathrm{s}$ & $20 \mathrm{mg} / \mathrm{s}$ & $30 \mathrm{mg} / \mathrm{s}$ \\
\hline $\mathrm{Xe}^{0} \rightarrow \mathrm{Xe}^{1+}$ ionization rate $\left(1 / \mathrm{m}^{3} / \mathrm{s}\right)$ & $3.3 \times 10^{23}$ & $8.0 \times 10^{23}$ & $1.3 \times 10^{24}$ \\
$\mathrm{Xe}^{1+} \rightarrow \mathrm{Xe}^{2+}$ ionization rate $\left(1 / \mathrm{m}^{3} / \mathrm{s}\right)$ & $1.6 \times 10^{22}$ & $8.0 \times 10^{22}$ & $1.9 \times 10^{23}$ \\
$\mathrm{Xe}^{0} \rightarrow \mathrm{Xe}^{2+}$ ionization rate $\left(1 / \mathrm{m}^{3} / \mathrm{s}\right)$ & $8.7 \times 10^{21}$ & $1.7 \times 10^{22}$ & $3.3 \times 10^{22}$ \\
$1^{\text {st }}$ term on RHS of Eqn. 8 & 0.03 & 0.02 & 0.03 \\
$2^{\text {nd }}$ term on RHS of Eqn. 8 & 0.05 & 0.10 & 0.15 \\
$n_{i}^{+} / n_{n}$ & 0.08 & 0.13 & 0.18 \\
\hline \hline
\end{tabular}

The increased $\alpha_{\mathrm{m}}$ due to higher discharge voltage or anode flow rate was combined into a single variable by examining its dependency with discharge power, as shown in Figure 16b. $\alpha_{\mathrm{m}}$ closely followed a linearly decreasing trend with power, consistent with the observed trends with voltage and flow rate. The uncorrected data at $300 \mathrm{~V}$ are also shown for reference in Figure 16a. Since $\alpha_{\mathrm{m}}$ directly affects the mass utilization efficiency, if CEX corrections were not made to the data, uncertainty of $1-5 \%$ would result. This uncertainty was larger than uncertainties in other quantities used in performance models and could lead to misinterpretations of thruster physics with operating condition.

This study also sought to determine whether single-point measurements were a sufficiently accurate gauge of the plume-averaged quantity. This was of interest because single point measurements are significantly easier to implement in the laboratory due to the size and mass of current $\mathrm{E} \times \mathrm{B}$ probe designs that make translating the probe around the plume somewhat challenging. To evaluate the error introduced by single point measurements, we compared the local $\alpha_{\mathrm{m}}$ at thruster centerline $\left(0^{\circ}\right)$ and channel centerline $\left(3^{\circ}\right)$ in Figure 16b. Both followed a similar linear trend of the plume-averaged $\alpha_{\mathrm{m}}$ with discharge power. When compared to the plume-averaged $\alpha_{\mathrm{m}}$ the average uncertainty (mean across all powers) introduced by taking a single point measurement was approximately $3.5 \%$ and $1.5 \%$ when taken from thruster centerline and channel centerline, respectively. The error at thruster centerline ranged from $1 \%$ at the low discharge powers to nearly $8 \%$ at the highest powers. The error at discharge channel centerline ranged from $<0.1 \%$ to $2 \%$, with a single outlier at $5 \%$ at $600 \mathrm{~V} 10 \mathrm{mg} / \mathrm{s}$. The channel centerline measurement therefore resulted in much less deviation from the plume-averaged values and exhibited a smaller spread in this deviation as a function of discharge power.

Based on these data, a channel centerline measurement would add no more than $2 \%$ uncertainty over a wide power range. However, this is in addition to the uncertainty in $\alpha_{m}$ due to the analysis of the probe spectra, which was estimated to be approximately $2 \%$. Thus, the total uncertainty of a single-point measurement was between $3-4 \%$, which was on the order of the uncertainty in the anode efficiency derived from thrust stand measurements, which were typically $2-4 \%$. Given that there were significant errors in the other plasma measurements used in the performance models (e.g., ion energy, plume divergence), plume-averaged values for the multiply-charged ions are recommended when fine changes in the thruster operating condition are being studied (e.g., magnetic field effects for a given operating condition). If the experiment is aimed more at understanding thruster physics over large throttling ranges of voltage and current, single-point measurements on channel centerline may be sufficient. 

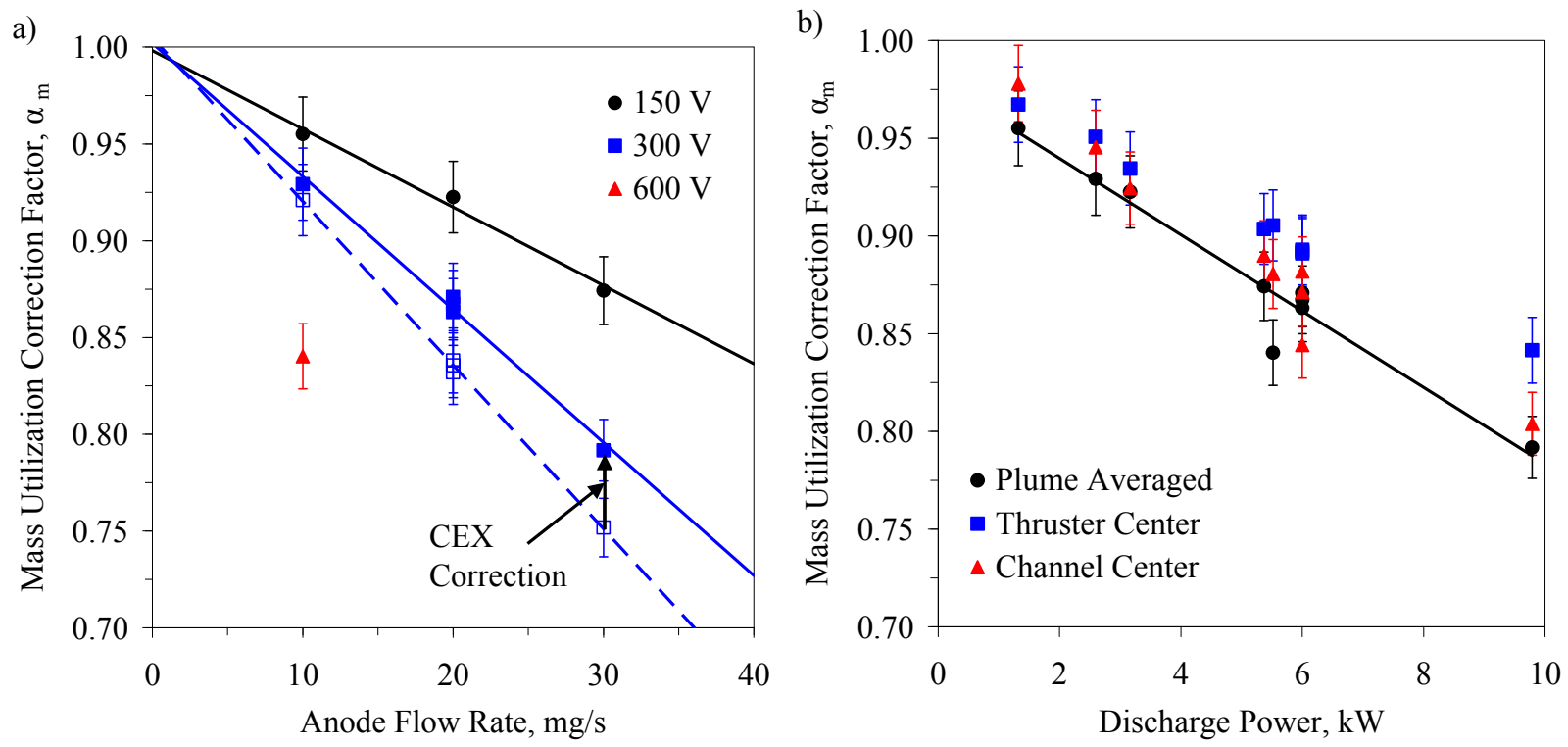

Figure 16. a) Plume-averaged $\alpha_{m}$ versus anode mass flow rate, b) $\alpha_{m}$ versus discharge power for plumeaverage, thruster center, and channel center quantities.

\section{B. Comparison with JPL and HPHall Results}

The centerline and plume-averaged $\mathrm{Xe}^{1+}$ current fractions measured by the $\mathrm{E} \times \mathrm{B}$ probe at $\mathrm{UM}$ are compared to centerline measurements at JPL [7], and plume-averaged values derived from HPHall plasma simulations [3] in Figure 17. Since HPHall did not model $\mathrm{Xe}^{3+}$, the $\mathrm{Xe}^{2+}$ and $\mathrm{Xe}^{3+}$ have been combined for the experimental measurements for consistency with the model. This approach was sufficient as long as $\mathrm{Xe}^{3+}$ did not comprise a large fraction of the discharge current. This limitation appeared to be violated at $30 \mathrm{mg} / \mathrm{s}$ where there was a significant difference between the experimental and simulation results. The UM and HPHall results were reported at 10, 20, and $30 \mathrm{mg} / \mathrm{s}$, and the JPL results were from 10 and $20 \mathrm{mg} / \mathrm{s}$ in Figure 17. All four sets of data were characterized by the same linear trend with flow rate shown in Section IV.A. There was excellent agreement (within 1\%) between the centerline measurements at UM, JPL, and HPHall simulations at $20 \mathrm{mg} / \mathrm{s}$. The HPHall $\mathrm{Xe}^{1+}$ current fraction was approximately $5 \%$ lower than the UM result at $10 \mathrm{mg} / \mathrm{s}$ and $9 \%$ higher at $30 \mathrm{mg} / \mathrm{s}$. The UM plume-averaged current fraction matched well with the JPL and HPHall results at $10 \mathrm{mg} / \mathrm{s}$ (within 1\%), but the JPL result was $5 \%$ higher at $20 \mathrm{mg} / \mathrm{s}$ and the HPHall result was 7 and $29 \%$ higher at 20 and $30 \mathrm{mg} / \mathrm{s}$, respectively. Overall, these results consistently demonstrated the linear dependence of the $\mathrm{Xe}^{1+}$ current fraction with anode mass flow rate, while the absolute differences in the various values were driven by the details of the experiment or the model. 


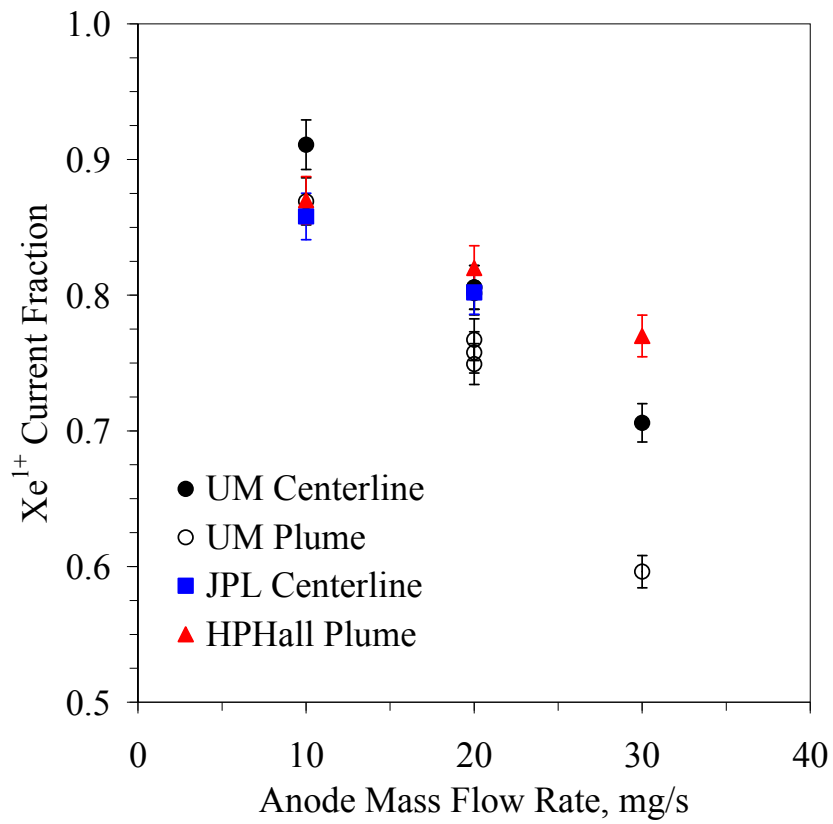

Figure 17. Comparison of $\mathrm{Xe}^{1+}$ current fraction for $\mathrm{UM}$ centerline and plume-averaged, JPL centerline, and HPHall plume-averaged results.

\section{Conclusion}

This study showed that the angular variation of the local ion current fractions, and hence, local $\alpha_{\mathrm{m}}$, contributed to a lower plume-averaged $\alpha_{\mathrm{m}}$ when compared to taking a single measurement on thruster centerline. Typically the fraction of $\mathrm{Xe}^{2+}$ increased by the drop in $\mathrm{Xe}^{1+}$, while $\mathrm{Xe}^{3+}$ remained approximately constant at all angles from thruster centerline. At $300 \mathrm{~V}$, the plume-averaged $\mathrm{Xe}^{1+}$ current fraction decreased with increased flow rate, with fractions of $0.87,0.75$, and 0.60 at 10,20 , and $30 \mathrm{mg} / \mathrm{s}$, respectively. The current fraction of $\mathrm{Xe}^{1+}$ also decreased with increased discharge voltage with values of $0.92,0.87$, and 0.70 at 150,300 , and $600 \mathrm{~V}$, respectively. Based on the variation of current fractions, the plume-averaged $\alpha_{\mathrm{m}}$ also decreased with discharge voltage and anode flow rate. The plume-averaged $\alpha_{\mathrm{m}}$ was $0.96,0.92$, and 0.88 at $300 \mathrm{~V}, 10,20$, and $30 \mathrm{mg} / \mathrm{s}$, respectively and $0.97,0.96$, and 0.90 at $10 \mathrm{mg} / \mathrm{s}, 150,300$, and $600 \mathrm{~V}$, respectively. The increasing fraction of multiply-charged ions (decrease in $\alpha_{\mathrm{m}}$ ) with discharge voltage was attributed to the increase in electron temperature. The increasing fraction of multiplycharged ions with anode flow rate was explained by the increasing ratio of $\mathrm{Xe}^{1+}$ to neutral $\mathrm{Xe}$ found by plasma simulations in HPHall.

The CEX correction method performed well, producing plume-averaged $\alpha_{\mathrm{m}}$ that were within $0.5 \%$ of each other at 8,10 , and 12 thruster diameters. The correction due to CEX was on the order of $1-5 \%$, depending on operating condition, exceeding the errors introduced by other parameters used in performance models (e.g., ion energy, plume divergence). This indicated that the CEX correction was an integral part of the analysis of $\mathrm{E} \times \mathrm{B}$ probe spectra for use in performance models.

The plume-averaged $\alpha_{\mathrm{m}}$ linearly varied with the discharge power. The plume-averaged $\alpha_{\mathrm{m}}$ deviated by $3.5 \%$ from the thruster centerline value and by an average of $1.5 \%$ from the channel centerline value over a range of discharge powers from approximately 1 to $10 \mathrm{~kW}$. Although the error associated with a single point measurement was not negligible, the resources necessary to record angularly-resolved probe measurements must be balanced by the realities of actuating the $\mathrm{E} \times \mathrm{B}$ probe through the plume. For studies focused on fine changes in thruster performance, plume-averaged quantities are likely to be a necessity, while studies concerned more with the behavior of the thruster over large throttling ranges can likely rely only on single-point measurements on discharge channel centerline, provided that appropriate error bounds are used based on the results of this study. 


\section{Appendix}

A summary of the thruster operating conditions and the relevant CEX-corrected parameters (plume-averaged species fractions, current fractions, $\alpha_{\mathrm{m}}(\Sigma(\Omega / \mathrm{Z})), \Sigma(\Omega / \sqrt{\mathrm{Z}}), \eta_{\mathrm{q}}$, and Q) are included in Table 2 .

Table 2: Summary of thruster operating conditions and relevant parameters derived from $E \times B$ probe spectra.

\begin{tabular}{ccccccccccccc}
\hline \hline Diameters & $\mathrm{V}_{\mathrm{d}}, \mathrm{V}$ & $\dot{m}_{a}, \mathrm{mg} / \mathrm{s}$ & $\zeta_{1}$ & $\zeta_{2}$ & $\zeta_{3}$ & $\Omega_{1}$ & $\Omega_{2}$ & $\Omega_{3}$ & $\Sigma(\Omega / \mathrm{Z})$ & $\Sigma(\Omega / \sqrt{ } \mathrm{Z})$ & $\eta_{\mathrm{q}}$ & $\mathrm{Q}$ \\
\hline 8 & 150 & 10 & 0.971 & 0.072 & 0.018 & 0.916 & 0.067 & 0.017 & 0.955 & 0.973 & 0.992 & 1.032 \\
8 & 150 & 20 & 0.907 & 0.120 & 0.033 & 0.855 & 0.113 & 0.031 & 0.923 & 0.954 & 0.986 & 1.058 \\
8 & 150 & 30 & 0.811 & 0.198 & 0.052 & 0.765 & 0.186 & 0.049 & 0.874 & 0.925 & 0.978 & 1.101 \\
\hline 8 & 300 & 10 & 0.922 & 0.105 & 0.034 & 0.869 & 0.099 & 0.032 & 0.929 & 0.957 & 0.987 & 1.053 \\
8 & 300 & 20 & 0.795 & 0.193 & 0.073 & 0.749 & 0.182 & 0.069 & 0.863 & 0.918 & 0.976 & 1.110 \\
10 & 300 & 20 & 0.804 & 0.183 & 0.074 & 0.758 & 0.173 & 0.070 & 0.867 & 0.920 & 0.976 & 1.106 \\
12 & 300 & 20 & 0.814 & 0.167 & 0.080 & 0.767 & 0.157 & 0.076 & 0.871 & 0.922 & 0.976 & 1.101 \\
8 & 300 & 30 & 0.632 & 0.347 & 0.081 & 0.596 & 0.327 & 0.076 & 0.792 & 0.875 & 0.968 & 1.191 \\
\hline 8 & 600 & 10 & 0.746 & 0.242 & 0.073 & 0.703 & 0.228 & 0.068 & 0.840 & 0.904 & 0.973 & 1.136 \\
\hline \hline
\end{tabular}

\section{Acknowledgments}

The authors would like to thank Mr. Adam Shabshelowitz for his assistance with the experimental setup and data acquisition. The first author has been supported throughout his graduate studies by the NASA Michigan Space Grant Consortium Fellowship, NASA Harriett Jenkins Pre-doctoral Fellowship Program, and the University of Michigan Rackham Merit Fellowship.

The authors would like to acknowledge and thank the Air Force Office of Scientific Research (AFOSR) for funding this research. Dr. Mitat Birkan is the Project Manager for Grant FA9550-06-1-0105.

Portions of this research were carried out at the Jet Propulsion Laboratory, California Institute of Technology, under a contract with the National Aeronautics and Space Administration.

\section{References}

[1] Koppel, C. and Estublier, D., "The Smart-1 Electric Propulsion Subsystem," 39th AIAA/ASME/SAE/ASEE Joint Propulsion Conference, AIAA-2003-4545, Huntsville, AL, Jul. 20-23, 2003.

[2] Hofer, R. R., "Development and Characterization of High-Efficiency, High-Specific Impulse Xenon Hall Thrusters," Ph.D. Dissertation, Dept. of Aerospace Engineering, University of Michigan, Ann Arbor, MI, 2004.

[3] Hofer, R. R., Katz, I., Mikellides, I. G., Goebel, D. M., Jameson, K. K., et al., "Efficacy of Electron Mobility Models in Hybrid-PIC Hall Thruster Simulations," AIAA/ASME/SAE/ASEE Joint Propulsion Conference, AIAA-2008-4924, Hartford, CT, Jul. 20-23, 2008.

[4] Larson, C. W., Brown, D. L. and Hargus, W. A., "Thrust Efficiency, Energy Efficiency and the Role of VDF in Hall Thruster Performance Analysis," 43rd AIAA/ASME/SAE/ASEE Joint Propulsion Conference, AIAA-2007-5270, Cincinnati, OH, Jul. 8-11, 2007.

[5] Kim, S. W. and Gallimore, A. D., "Plume Study of a $1.35 \mathrm{~kW}$ SPT-100 Using an ExB Probe," 35th AIAA/ASME/SAE/ASEE Joint Propulsion Conference, AIAA-1999-2423, Los Angeles, CA., Jun. 20-24, 1999.

[6] Ekholm, J. M. and Hargus, W. A., "ExB Measurements of a $200 \mathrm{~W}$ Xenon Hall Thruster," 41st AIAA/ASME/SAE/ASEE Joint Propulsion Conference, AIAA-2005-4405, Tucson, AZ, Jul. 10-13, 2005.

[7] Shastry, R., Hofer, R. R., Reid, B. M. and Gallimore, A. D., "Method for Analyzing ExB Probe Spectra from Hall Thruster Plumes," 44th AIAA/ASME/SAE/ASEE Joint Propulsion Conference, AIAA-2008-4647, Hartford, CT, Jul. 2023, 2008.

[8] Walker, M. L. R., "Effects of Facility Backpressure on the Performance and Plume of a Hall Thruster," Dept. of Aerospace Engineering, University of Michigan, Ann Arbor, MI, 2005.

[9] Haas, J. M., Hofer, R. R., Brown, D. L., Reid, B. M. and Gallimore, A. D., "Design of the \#\# Hall Thruster for High Thrust/Power Investigation," Presented at the 54th JANNAF Propulsion Meeting, Denver, CO, May 14-17, 2007.

[10] Reid, B. M., Gallimore, A. D., Hofer, R. R., Li, Y. and Haas, J. M., "Anode Design and Verification for the \#\# Hall Thruster," Presented at the 54th JANNAF Propulsion Meeting, Denver, CO, May 14-17, 2007.

[11] Hofer, R. R., Goebel, D. M. and Watkins, R. M., "Compact LaB6 Hollow Cathode for the \#\# Hall Thruster," Presented at the 54th JANNAF Propulsion Meeting, Denver, CO, May 14-17, 2007. 
[12] Brown, D. L., Reid, B. M., Gallimore, A. D., Hofer, R. R., Haas, J. M., et al., "Performance Characterization and Design Verification of the \#\# Laboratory Model Hall Thruster," Presented at the 54th JANNAF Propulsion Meeting, Denver, CO, May 14-17, 2007.

[13] Dymond, J. H. and Smith, E. B., The Virial Coefficients of Pure Gases and Mixtures, a Critical Compilation, Oxford University Press, New York, 1980.

[14] Walker, M. L. R., Victor, A. L., Hofer, R. R. and Gallimore, A. D., "Effect of Backpressure on Ion Current Density Measurements in Hall Thruster Plumes," Journal of Propulsion and Power, 21, 3, 408-415, 2005.

[15] Kim, S. W., "Experimental Investigations of Plasma Parameters and Species-Dependent Ion Energy Distribution in the Plasma Exhaust Plume of a Hall Thruster," Ph. D. Dissertation, Dept. of Aerospace Engineering, University of Michigan, Ann Arbor, 1999.

[16] Hofer, R. R., Jankovsky, R. S. and Gallimore, A. D., "High-Specific Impulse Hall Thrusters, Part 2: Efficiency Analysis," Journal of Propulsion and Power, 22, 4, 732-740, 2006.

[17] Hofer, R. R. and Gallimore, A. D., "Ion Species Fractions in the Far-Field Plume of a High-Specific Impulse Hall Thruster," 39th AIAA/ASME/SAE/ASEE Joint Propulsion Conference, AIAA 2003-5001, Huntsville, AL, Jul. 20-23, 2003.

[18] Katz, I., Hofer, R. R. and Goebel, D. M., "Ion Current in Hall Thrusters," IEEE Journal, 2008.

[19] Hofer, R. R., Mikellides, I., Katz, I. and Goebel, D. M., "BPT-4000 Hall Thruster Discharge Chamber Erosion Model Comaprison with Qualification Life Test Data," 30th International Electric Propulsion Conference, IEPC-2007-267, Florence, Italy, Sep. 17-20, 2007.

[20] Kim, V., Grdlichko, D., Kozlov, V., Lazurenko, A., Popkov, G. B., et al., "Local Plasma Parameter Measurements by Nearwall Probes inside the SPT Accelerating Channel under Thruster Operation with Kr," 38th AIAA/ASME/SAE/ASEE Joint Propulsion Conference, AIAA-2002-4108, Indianapolis, IN, Jul. 7-10, 2002.

[21] Haas, J. M. and Gallimore, A. D., "Considerations on the Role of the Hall Current in a Laboratory-Model Thruster," IEEE Transactions on Plasma Science, 30, 2, 687- 697, 2002.

[22] Linnell, J. A. and Gallimore, A. D., "Internal Plasma Potential Measurements of a Hall Thruster Using Plasma Lens Focusing," Physics of Plasmas, 13, 103504, 2006.

[23] Staack, D., Raitses, Y. and Fisch, N. J., "Temperature Gradient in Hall Thrusters," Applied Physics Letters, 84, 16, 30283030, 2004.

[24] Reid, B. M. and Gallimore, A. D., "Plasma Potential Measurements in the Discharge Channel of a 6-kW Hall Thruster," 44th AIAA/ASME/SAE/ASEE Joint Propulsion Conference, AIAA-2008-5185, Hartford, CT, Jul. 20-23, 2008. 